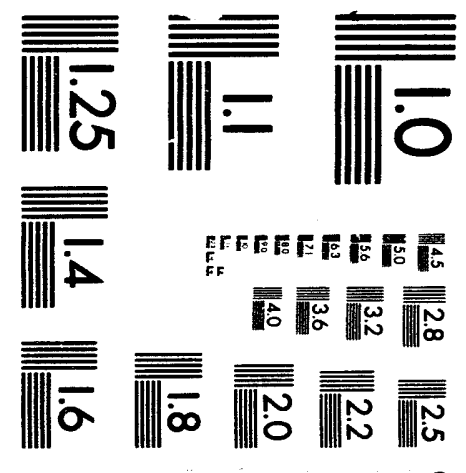



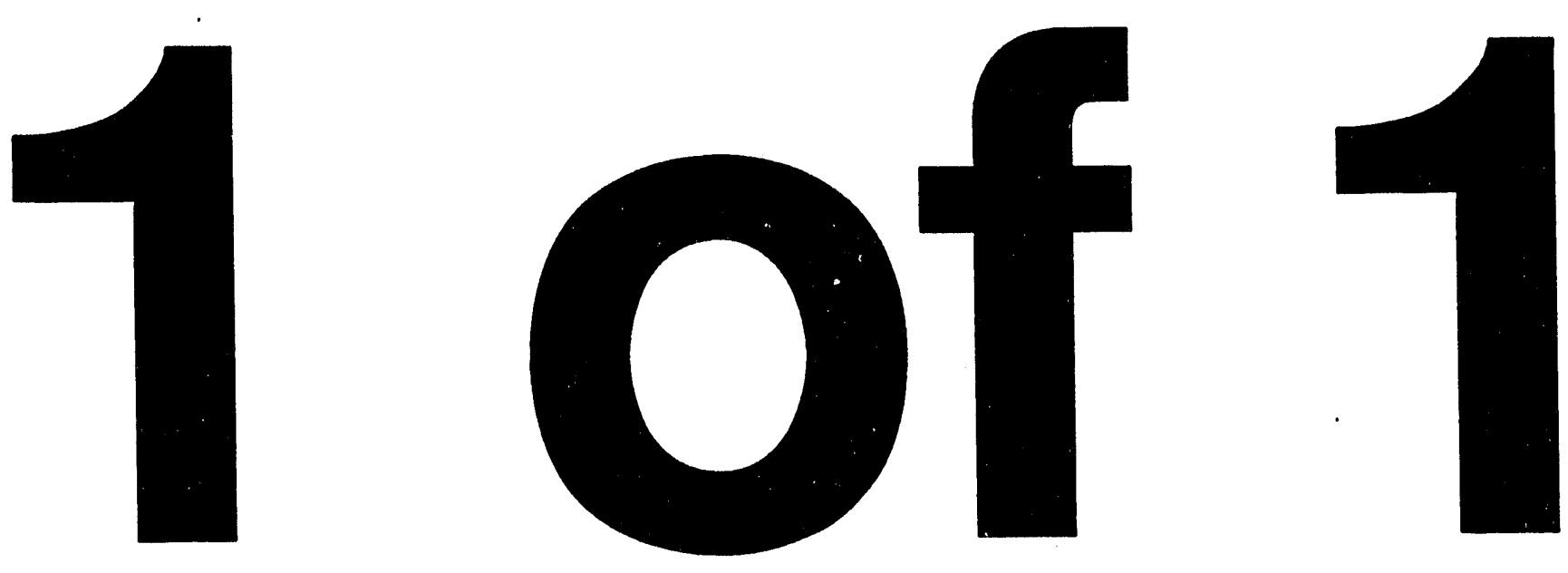


\title{
WINDOW 4.0: Documentation of Calculation Procedures
}

\author{
E.U. Finlayson, D.K. Arasteh, C. Huizenga, M.D. Rubin \\ Energy and Environment Division \\ Lawrence Berkeley Laboratory \\ University of California \\ Berkeley, California 94720 \\ and \\ M.S. Reilly \\ Enermodal Engineering, Inc. \\ Denver, CO 80218
}

July 1993

This work was supported by the Assistant Secretary for Energy Efficiency and Renewable Energy, Office of Building Technologies, Building Systems and Materials Division of the U.S. Department of Energy under Contract No. DEAC03-76SF00098. 


\section{TABLE OF CONTENTS}

1.0 INTRODUCTION

1.1 Overview of Documentation Structure

2.0 THE MAIN SCREEN

2.1 Calculation of Component Areas 2

2.1.1 Calculation of the Frame Area 3

2.1.2 Calculation of Divider Area 5

2.1.3 Calculation of Edge-of-glass Area 6

2.1.4 Calculation of Divider Edge Area 6

2.1.5 Calculation of the Glass Area $\quad 7$

2.2 Calculation of Total Window Properties 7

2.2.1 Window U-Value 7

2.2.2 Window Solar Heat Gain Coefficient $\quad 8$

2.2.3 Window Shading Coefficient 9

2.2.4 Window Visible Transmittance 9

2.3 Combination Windows 9

3.0 GLASS LIBRARY 9

$\begin{array}{ll}\text { 3.1 Calculation of Average Optical Properties } & 10\end{array}$

3.1.1 Numerical Integration of Spectral Integral 11

3.2 Calculation of Hemispherical Emittance 11

3.3 Thermal Conductivity of Laminated Glass Products 12

4.0 GAS LIBRARY 12

$\begin{array}{ll}\text { 4.1 Calculations of Properties of Gas Mixtures } & 12\end{array}$

5.0 GLAZING SYSTEM LIBRARY 13

5.1 Center of Glass U-value 13

5.2 Center of Glass Solar Heat Gain Coefficient $\quad 14$

$\begin{array}{ll}\text { 5.3 Center of Glass Shading Coefficient } & 14\end{array}$

5.4 Center of Glass Visible Transmittance $\quad 14$

$\begin{array}{ll}5.5 \text { Relative Heat Gain } & 14\end{array}$

5.6 Effective Conductivity for Gas Cavities $\quad 14$

6.0 FRAME/DIVIDER LIBRARY 15

6.1 ASHRAE/LBL Frames 16

$\begin{array}{ll}\text { 6.1.1 The Edge U-value } & 16\end{array}$

6.2 Generic Frames 16

6.3 FRAME 3.0 Frames $\quad 16$

6.3.1 One Glazing System Simulation - Type I 17

6.3.2 Two Glazing System Simulations - Type II and III $\quad 18$ 
6.3.3 Four Glazing System Simulation - Type IV 20

6.4 LBL Dividers $\quad 22$

6.5 Generic Dividers $\quad 22$

6.6 FRAME 3.0 Dividers 23

7.0 Optical Properties 23

7.1 Determination of Overall Glazing System Properties 24

$\begin{array}{ll}\text { 7.1.1 Overall Transmittance and Reflectance } & 24\end{array}$

7.1.2 Calculation of Absorption of Each Layer $\quad 25$

7.2 Calculation of Angular Properties 25

7.2.1 Angular Properties for Uncoated Glass 26

7.2.2 Angular Properties for Coated Glass 28

7.3 Calculation of Hemispherical values 29

7.4 Ultraviolet Transmittance 29

$\begin{array}{ll}7.5 \text { Calculation of the Color Properties } & 29\end{array}$

$\begin{array}{ll}\text { 7.5.1 Calculation of the Chromaticity coordinates } & 30\end{array}$

7.5.2 Calculation of the Dominant Wavelength and Purity 30

7.5.3 Calculation of the CIE $L^{*}, a^{*}, b^{*}$ Values 31

8.0 TEMPERATURE SCREEN

8.1 Temperature Profile $\quad 32$

8.2 Outline of the Temperature Profile Algorithm $\quad 32$

8.2.1 Initialize Calculation $\quad 34$

$\begin{array}{ll}\text { 8.2.2 Begin Iteration } & 34\end{array}$

$\begin{array}{ll}\text { 8.2.3 Calculation of radiative source strength } & 34\end{array}$

8.2.4 Calculation of the radiative conductance coefficients 34

8.2.5. Calculation of convective film coefficients $\quad 35$

8.2.6 Calculation of the resistances of exterior surfaces and gaps 37

8.2.7 Calculation of the heat transfer through each layer 38

$\begin{array}{ll}\text { 8.2.8 Calculation of surface temperatures } & 38\end{array}$

$\begin{array}{ll}\text { 8.2.9 Calculation of a new temperature distribution } & 38\end{array}$

8.2.10 Check for convergence or maximum iterations $\quad 39$

8.3 Condensation Calculation 39

8.4 Effective Night Sky Temperature $\quad 39$

\begin{tabular}{ll}
9.0 & CONCLUSION \\
\hline
\end{tabular}

10.0 REFERENCES AND ACKNOWLEDGMENTS

$\begin{array}{ll}11.0 \text { NOMENCLATURE } & 43\end{array}$ 


\subsection{INTRODUCTION}

WINDOW 4.0 is a publicly available IBM PC compatible computer program developed by the Building Technologies Group at the Lawrence Berkeley Laboratory for calculating the thermal and optical properties necessary for heat transfer analyses of fenestration products. This report explains the calculation methods used in WINDOW 4.0 and is meant as a tool for those interested in understanding the procedures contained in WINDOW 4.0. All the calculations are discussed in the International System of units (SI).

WINDOW 4.0 is the latest in a series of programs released by the Lawrence Berkeley Laboratory. The WINDOW program has is roots in a paper detailing a method for calculating heat transfer through windows [Rubin, 1982]. WINDOW 4.0 replaces the widely used 3.1 version. Although WINDOW 4.0 is a major revision, many of the algorithms used in WINDOW 4.0 build upon those previously documented [Arasteh, 1989b], [Furler, 1991]. This report documents the calculations that are unchanged from WINDOW 3.1, as well as those calculations that are new to WINDOW 4.0. This report uses the organization of the WINDOW 4.0 program. Results displayed on a WINDOW 4.0 screen are discussed in a section describing that screen. In the conclusion the aspects of the calculation method currently slated for revision are discussed. A glossary of variables used throughout the report is found in Section 11 .

\subsection{Overview of Documentation Structure}

This section outlines the calculations as they are discussed in this report. Calculations are discussed in the context of the screen on which they appear.

MAIN SCREen: The calculation of total window properties, U-value, Shading Coefficient, Solar Heat Gain Coefficient and Visible Transmittance is associated with the MAIN SCREEN. The calculations of properties for combination windows is also associated with the MAIN SCREEN.

WINDOW LIBRARY: The WINDOW LIBRARY stores properties of windows that are created on the MAIN SCREEN. No calculations are associated with this screen.

GLASS LIBRARY: The GLASS LIBRARY reports glazing layer properties. If spectral values of transmittance and reflectance are available, weighted average optical properties are obtained by integrating these properties over various wavelength ranges. The method for determining the average optical properties for the solar, visible and infrared ranges, for a single glazing layer, is described in this section. In WINDOW 3.1 the user was limited to single values for optical properties of a glazing layer. The inclusion of spectral data is new to WINDOW 4.0. The procedure for calculating average optical properties for a multi-layer glazing system is discussed in the section describing the OPTICAL PROPERTIES SCREEN, see Section 7.

GAS LIBRARY: Within the GAS LBBRARY the properties of two different mixtures of gasses; Air/Argon/Krypton and $\mathrm{SF}_{6} /$ Argon are calculated. This calculation is unchanged from WINDOW 3.1. The method has been presented before [Arasteh, 1989b] but is included in this report for completeness. Changes to the GAS LIBRARY in WNNDOW 4.0, not related to calculation methods, include the density of Argon, the English unit (IP) values of the derivative of the Prandtl Number with respect to temperature and the addition of properties for $\mathrm{CO}_{2}$.

GLAZING SYSTEM LIBRARY: The center-of-glass thermal properties; U-value, Shading Coefficient, Solar Heat Gain Coefficient, Visible Transmittance and Relative Heat Gain Coefficient, are calculated within the GLAZING SYSTEM LIBRARY. The Effective Conductivity of the glazing system is also calculated in this 
library. Discussion of the calculation of optical properties for the glazing system is found in Section 7, OPTICAL PROPERTIES SCREEN. Discussion of the calculation of the center-of-glass temperature profile is found in Section 8, TEMPERATURE SCREEN.

ENVIRONMENTAL CONDITIONS LiBRaRY: This library is a display screen of generic and user defined data. In WINDOW 4.0 the user is able to specify an effective sky temperature $T_{\text {sky }}$ and an effective sky emittance, $\varepsilon_{\text {sky. }}$. This feature allows the user to anticipate the heat transfer from a window on a cold clear night. Nonstandard choices for $T_{\text {sky }}$ and $\varepsilon_{\text {sky }}$, affect the ambient temperature, $\theta_{\text {amb }}$, seen by the window and thus affect the heat transfer through the window. Calculation of $\theta_{a m b}$ is discussed in Section 8.4.

Frame / DIVIDER LIBRARY: These libraries have the same structure and will be discussed together. While they are primarily a data storage facility, they also contain the correlations used to calculate the Uvalues. The calculations for the edge-of-glass U-Value, the divider U-Value and the divider edge U-Value are discussed in this section. The coefficients for the edge U-Value calculation are slightly different from those used in WINDOW 3.1 although the classifications are the same. Dividers are new to this version as are all divider calculations. The interpolation scheme that allows WINDOW 4.0 to use frame elements imported from FRAME 3.0 is introduced here, for more information regarding the validation of this procedure see Beck [1993.]

Optical Properties SCReen: This screen displays optical properties for the total glazing system. This section discusses the calculation method used to combine individual glazing layers, either with single properties or with spectral properties, to obtain the optical properties for the total glazing system. Values for normal incidence are given as well as off-normal and hemispherical values. This screen also calculates the values of the absorptances of each glazing layer within the glazing system. For glazing systems made up of glazing layers represented by spectral data, additional calculations are performed. Two Ultraviolet transmittances are calculated: an average transmittance between 0.30 and $0.39 \mu \mathrm{m}$ and a damage weighted average between 0.30 and $0.50 \mu \mathrm{m}$. The damage weighted transmittance takes into account the variation of damage caused by irradiation at different wavelengths. Color calculations: purity; dominant wavelength and the CIE $L^{*}, a^{*}, b^{*}$ values, based on both transmittance and reflectance, are also discussed in conjunction with this screen.

TEMPERATURE SCREen: The TEMPERATURE SCREEN displays two center-of-glass temperature profiles and the Relative Humidity necessary for condensation to form. The resistance method used for calculating the temperature profiles is the same as that of WINDOW 3.1 [Arasteh 1989]. It is included in this report for completeness. Included in the discussion of this algorithm are the calculations of the film coefficients on the outside surfaces and within the gaps of the glazing system.

\subsection{THE MAIN SCREEN}

The total properties are displayed on the MAIN SCREEN of WINDOW 4.0. These properties are calculated for different operator types of both windows and doors. For simplicity both doors and windows will by referred to as windows in this report. Operating ypes include, for windows, horizontal and vertical sliders, picture, casement, awning and skylight and, for doors, single and double. Five components: the center-ofglass, the frame, the edge-of-glass, the dividers, and the divider edge, can make up the total unit. The number of glazing systems and frame elements required to model a window or door depends on the operator type selected. Determination of the center-of-glass properties is discussed in Section 5 which describes GLAZING SYSTEM LBBRARY calculations. Determination of the U-value for the frame, edge-of-glass, divider and divider-edge is discussed in Section 6 which describes the FRAME/DIVIDER LIBRARY. The total window properties displayed on the MAIN SCREEN are area-weighted properties. These properties are 
obtained by first multiplying the component property by the component area. These area-weighted component properties are then summed. The total window properties are determined by dividing the areaweighted sum by the total area of the window. The specifics of this calculation method are discussed in this section.

\subsection{Calculation of Component Areas}

The dimensions of the total window are input by the user on the MAN SCREEN. The program first calculates the total window area by multiplying the height by the width, then subdivides the total window area subdivided into component areas. WINDOW calculates five possible component areas: frame, divider, center-of-glass, edge-of-glass and divider edge, see Fig. 2.1. The calculation procedure for each of these components is considered separately. Another useful area is referred to as the vision area, as it is defined in this report the vision area includes all of the components of the window except the frame.
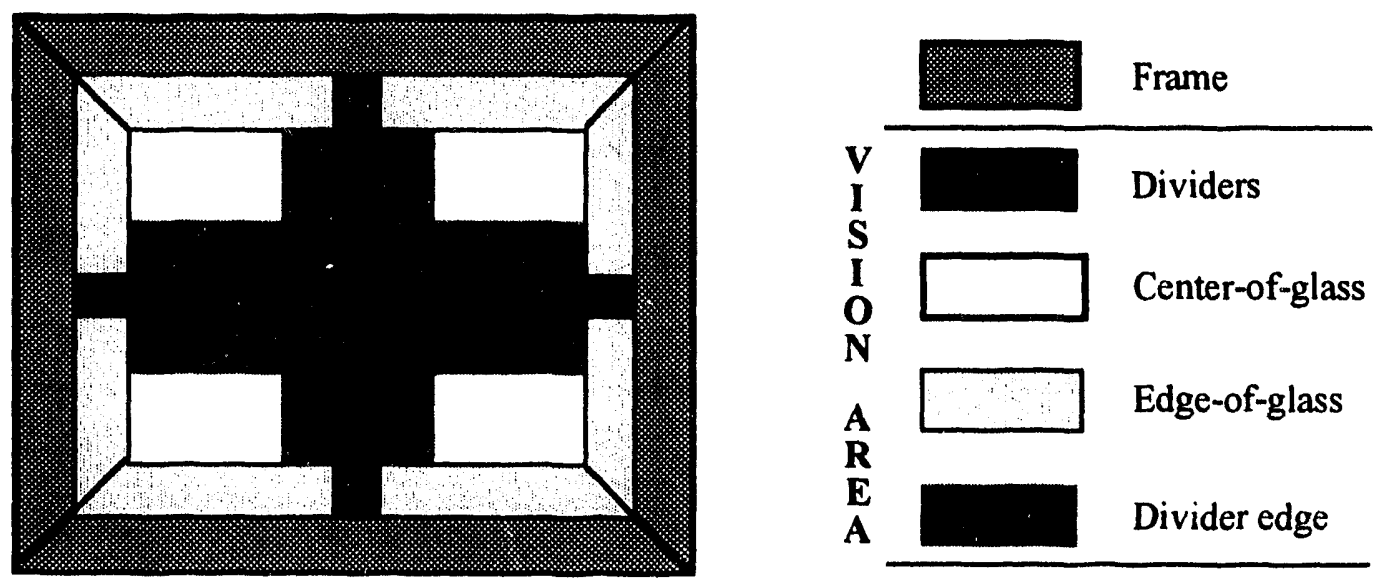

Figure 2.1 Schematic of the component areas that make up the total window area.

\subsubsection{Calculation of the Frame Area}

WINDOW 4.0 allows the user to specify the properties of the individual components that make up a total frame. The user selected operator type (fixed, vertical slider, horizontal slider) determines which components (headers, jambs, sills and meeting rail) are required to design a window. (In WINDOW 3.1 the user could specify only one set of properties for the entire frame.) Figure 2.2 shows a schematic for a window with one glazing system. Figure 2.3 shows a schematic for a window with two glazing systems. The frame pieces are shown with mitered corners, as they are considered in WINDOW 4.0.

\section{Calculation of Vision Area}

The vision area includes all the components of the window except for the frame elements. The dimensions of the vision area are determined by subtracting the Projected Frame Dimensions, $w_{i}$, from the total window dimensions. The vision area, $\mathrm{A}_{\mathrm{VISj}}$, is defined for the $\mathrm{j}^{\text {th }}$ glazing systems in the window:

$A_{V I S j}=V_{j} \times H_{j}$

Where $V_{j}$ is the vertical dimension and $H_{j}$ is the horizontal dimension of the vision area of the $j^{\text {th }}$ glazing system. For a window with one glazing system, see Fig. $2.2, \mathrm{j}=1$. The vertical and horizontal dimensions of the vision area, $\mathrm{V}_{1}$ and $\mathrm{H}_{1}$, are defined: 
$\mathrm{V}_{1}=\mathrm{V}_{\mathrm{TOT}}-\mathrm{w}_{1}-\mathrm{w}_{3}$

$\mathrm{H}_{1}=\mathrm{H}_{\mathrm{TOT}}-\mathrm{w}_{2}-\mathrm{w}_{4}$

For a horizontal slider type window, see Fig. $2.3, \mathrm{j}=1$ and 2 . The horizontal dimensions of the vision area, $\mathrm{H}_{1}$ and $\mathrm{H}_{2}$, are specified by the user on the main screen and the vertical dimensions are defined: .

$\mathrm{V}_{1}=\mathrm{V}_{\mathrm{TOT}}-\mathrm{w}_{2}-\mathrm{w}_{4}$

$\mathrm{V}_{2}=\mathrm{V}_{\mathrm{TOT}}-\mathrm{w}_{5}-\mathrm{w}_{7}$

The dimensions of the vision areas of a vertical slider type window are analogous to those of a horizontal slider type window with the horizontal and vertical orientations exchanged.

\section{Windows with One Glazing System}

The frame elements of windows with one glazing system, see Fig. 2.2, are trapezoidal. Eqs. 2.1.1f-i are used to calculate the areas of frame elements in a window with only one glazing system.

$$
\begin{aligned}
& A_{F_{1}}=w_{1}\left(H_{1}+.5\left(w_{2}+w_{4}\right)\right) \\
& A_{F_{2}}=w_{2}\left(V_{1}+.5\left(w_{1}+w_{3}\right)\right) \\
& A_{F_{3}}=w_{3}\left(H_{1}+.5\left(w_{2}+w_{4}\right)\right) \\
& A_{F_{4}}=w_{4}\left(V_{1}+.5\left(w_{1}+w_{3}\right)\right)
\end{aligned}
$$

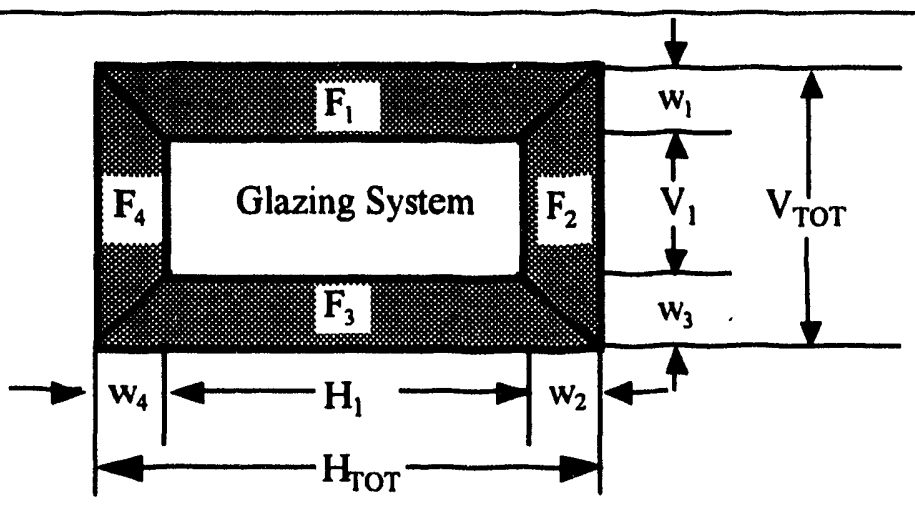

Figure 2.2 Schematic of a window with one glazing system.

\section{Windows with Two Glazing Systems}

Windows with two glazing systems, see Fig. 2.3, have the added complication of the mullion or meeting rail. The meeting rail is artificially divided in half for calculation purposes. The left half is associated with Glazing System 1 and the right half is associated with Glazing System 2. The meeting rail in a Vertical Slider is treated in an analogous manner. Equations 2.1.1j-p are used to calculate the areas of the various frame elements found in windows with two glazing systems.

$$
\begin{aligned}
& A_{F_{1}}=w_{1}\left(V_{1}+.5\left(w_{4}+w_{2}\right)\right) \\
& A_{F_{2}}=w_{2}\left(H_{1}+.5\left(w_{1}+w_{3}\right)\right) \\
& A_{F_{3}}=.5 w_{3}\left(V_{1}+V_{2}\right)
\end{aligned}
$$




$$
\begin{aligned}
& A_{F_{4}}=w_{4}\left(H_{1}+.5\left(w_{1}+w_{3}\right)\right) \\
& A_{F_{5}}=w_{5}\left(H_{2}+.5\left(w_{6}+w_{3}\right)\right) \\
& A_{F_{6}}=w_{6}\left(V_{2}+.5\left(w_{7}+w_{5}\right)\right) \\
& A_{F_{7}}=w_{7}\left(H_{2}+.5\left(w_{6}+w_{3}\right)\right)
\end{aligned}
$$

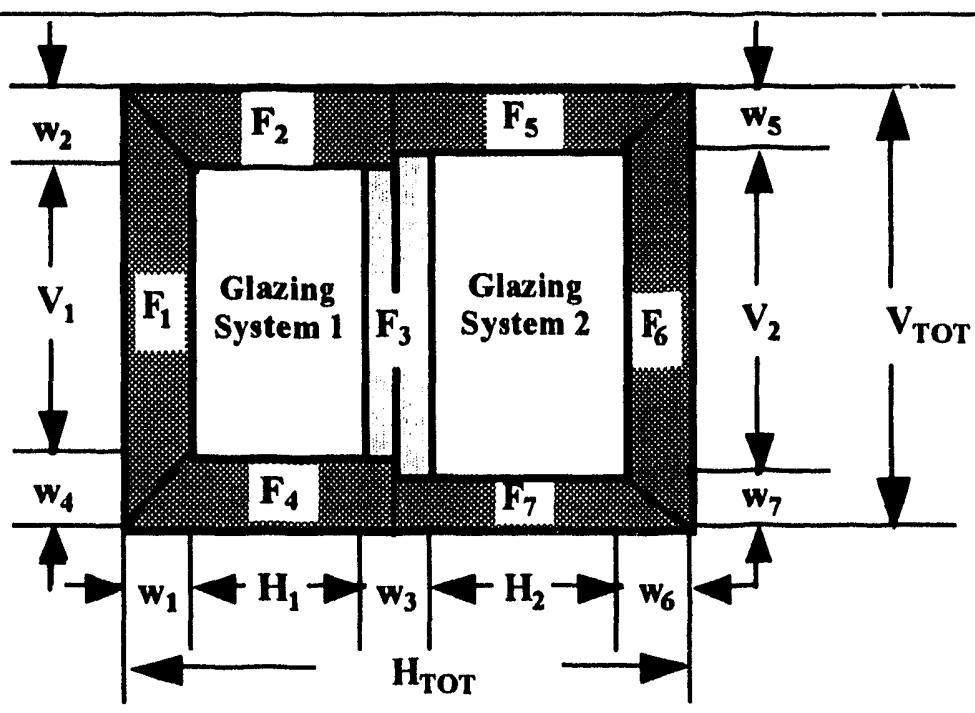

Figure 2.3 Schematic of window types with two glazing systems.

\subsubsection{Calculation of Divider Area}

A typical window with a system of dividers is shown in Fig. 2.4. The Projected Divider Dimension, $w_{D j}$, is the same for all dividers in a glazing system. The total divider area is the sum of the horizontal divider area plus the vertical divider area, less the area of overlap. The divider area for the jth glazing system is the product of the divider width, $\mathrm{w}_{\mathrm{D}}$; the dimension of the vision area; and the number of dividers, $\mathrm{N}$.

$$
A_{D_{j}}=\underbrace{w_{D_{j}} \times H_{j} \times N_{H_{j}}}_{\begin{array}{c}
\text { Horizontal } \\
\text { Divider Area }
\end{array}}+\underbrace{w_{D_{j}} \times V_{j} \times N_{V_{j}}}_{\begin{array}{c}
\text { Vertical } \\
\text { DividerArea }
\end{array}}-\underbrace{w_{D_{j}}^{2} \times N_{H_{j}} \times N_{V_{j}}}_{\begin{array}{c}
\text { DividerOverlap } \\
\text { Area }
\end{array}}
$$

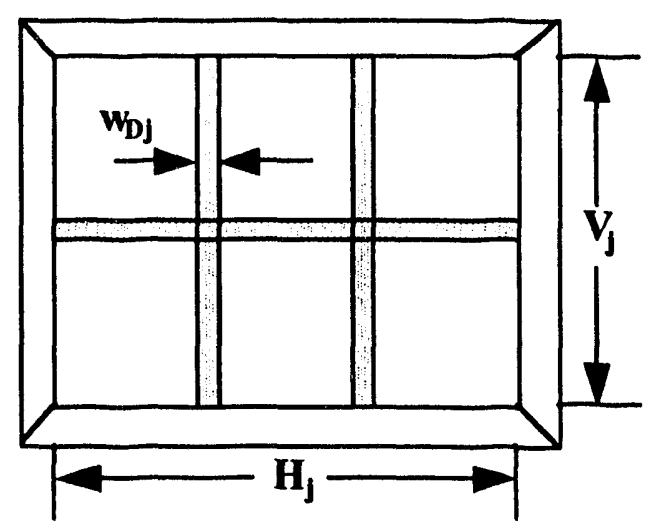

Figure 2.4 The divider area is shown shaded. In this example $\mathrm{N}_{\mathrm{H}}$, the number of horizontal dividers, equals 1 and $N_{v}$, the number of vertical dividers equals 2 . 


\subsubsection{Calculation of Edge-of-glass Area}

The edge-of-glass is the region of two-dimensional heat transfer, as opposed to the one-dimensional heat transfer in the center-of glass region. The edge-of-glass extends from the sightline and has a width, $w_{E}$, of $63.55 \mathrm{~mm}$. The thermal behavior of the edge region is strongly affected by the spacer and frame construction. The calculation of the edge U-value is discussed in Section 6.1. A separate edge area and edge-of-glass $U$-value is calculated for each frame element. Equations 2.1.3a and 2.1.3b are used to calculate the edge areas, $A_{E i, j}$, adjacent to $i^{\text {th }}$ frame element for the $j^{\text {th }}$ glazing system.

For horizontal frame elements: $\quad A_{E_{i, j}}=w_{E}\left(H_{j}-w_{E}-N_{V_{j}} \times w_{D_{j}}\right)$

For vertical frame elements:

$$
A_{E_{i}, j}=w_{E}\left(v_{j}-w_{E}-N_{H_{j}} \times w_{D_{j}}\right)
$$

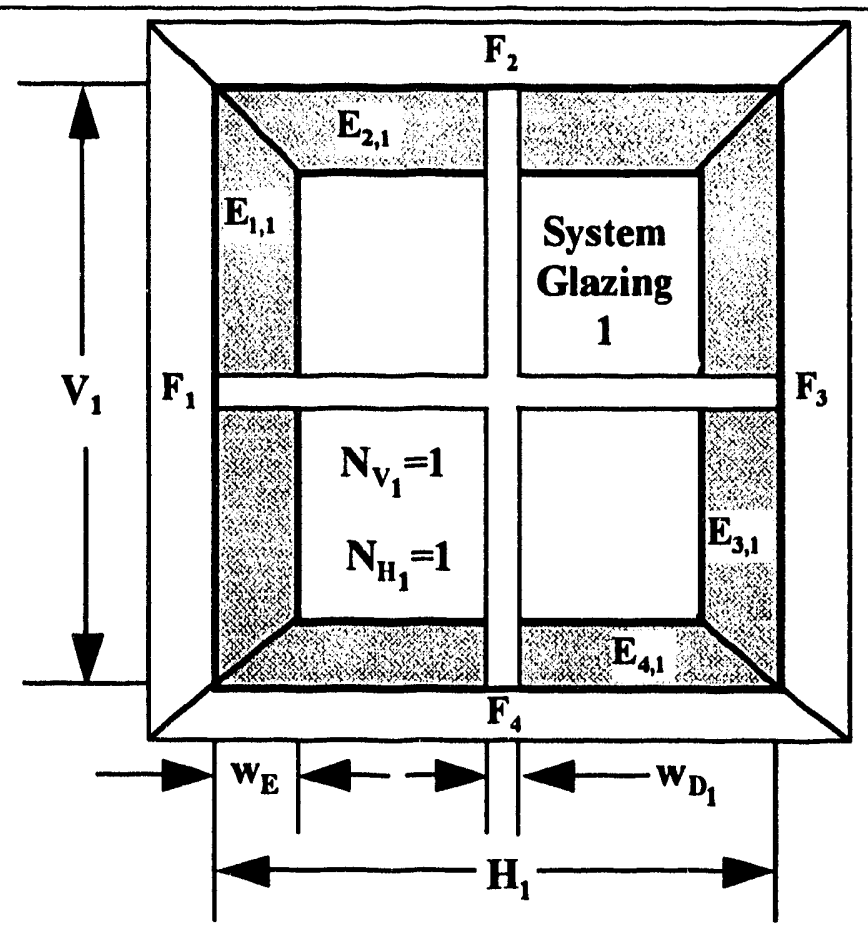

Figure 2.5 The edge-of-glass area is shown shaded. The value of the Edge U-value is related to the adjacent frame element as indicated.

\subsubsection{Calculation of Divider Edge Area}

The presence of dividers within an insulated glass unit can create a region of two-dimensional heat transfer in the glass near the dividers. This region is referred to as the divider edge area. The width of the divider edge $\left(w_{D E}\right)$ is the same as the width of the edge-of-glass, $63.55 \mathrm{~mm}$. The divider edge area is shown shaded in Fig. 2.6. It extends a width of $\mathrm{w}_{\mathrm{DE}}$ on either side of the divider, but does not extend into the area defined as the edge-of-glass area. The divider edge area for the jth glazing system is calculated as follows: 


$$
\begin{aligned}
& A_{D_{j}}=\underbrace{2 \times w_{D E}}_{\begin{array}{c}
\text { Edge width on } \\
\text { both side of the } \\
\text { divider }
\end{array}} \times(\underbrace{N_{H_{j}} \times\left(H_{j}-2 \times w_{E}\right)}_{\text {Total length of Horizontal Dividers }}+\underbrace{N_{V_{j}} \times\left(V_{j}-2 \times w_{E}\right)}_{\text {Total length of Vertical Dividers }}) \\
& -\underbrace{\mathrm{N}_{\mathrm{H}_{\mathrm{j}}} \times \mathrm{N}_{\mathrm{V}_{\mathrm{j}}}}_{\begin{array}{c}
\text { Total Number } \\
\text { of Dividers }
\end{array}} \times(\underbrace{4.0 \times \mathrm{w}_{\mathrm{DE}}^{2}}_{\text {Overlap of Divider Edge Area }}+\underbrace{4.0 \times \mathrm{w}_{\mathrm{E}} \times \mathrm{w}_{\mathrm{D}}}_{\text {Overlap of Divider Edge with } \perp \text { Divider }})
\end{aligned}
$$

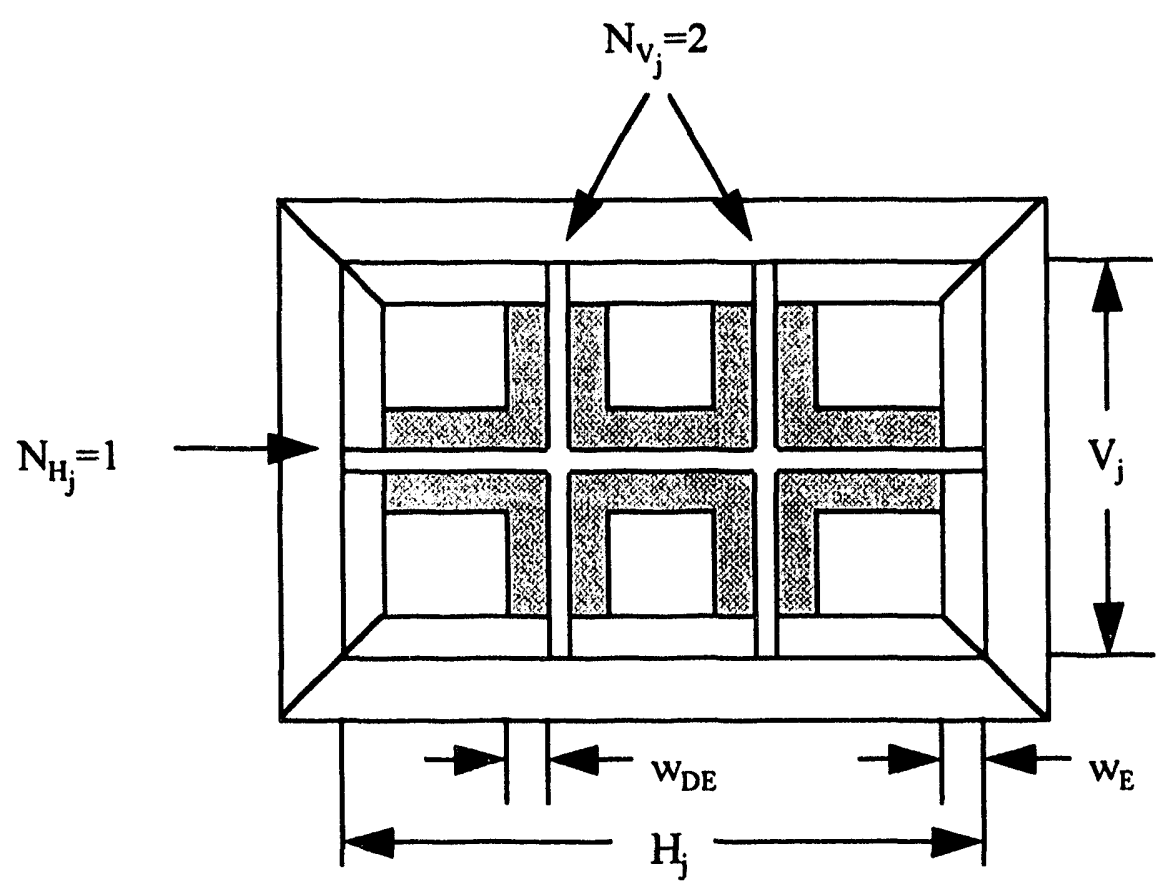

Figure 2.6. The divider edge is shown shaded. The divider edge U-value is a function of the center-ofglass U-value and the divider geometry with respect to the glazing system.

\subsubsection{Calculation of the Glass area}

The center-of-glass area of the jth glazing system, is calculated by subtracting the total edge-of-glass area, the divider area and the divider edge area for each glazing system from the vision area, see Eq. 2.1.1a:

$$
A_{C_{j}}=A_{V I S}-A_{D_{j}}-A_{D E j}-\sum_{i=1}^{M} A_{E_{i, j}}
$$

Where $M$ is the number of different frame elements that make up the total frame.

\subsection{Calculation of Total Window Properties}

\subsubsection{Window U-Value}

The total U-value for the window is the area-weighted average of the component U-values: 
$U_{T O T}=\left(\sum_{i}\left(U_{F_{i}} A_{F_{i}}+\sum_{j} U_{E_{i, j}} A_{E_{i, j}}\right)+\sum_{j}\left(U_{C_{j}} A_{C_{j}}+U_{D_{j}} A_{D_{j}}+U_{D E_{j}} A_{D E j}\right)\right) / A_{T O T}$

For single or planar combination windows, $A_{\text {TOT }}$ is the total window area. $A_{\text {TOT }}$ is the product of the user input dimensions of the height and width of the window. For nonplanar combination windows, $A_{\text {TOT }}$ is the projected area input by the user on the MAIN SCREEN. The calculation of the center-of-glass U-value is discussed in Section 5.2.1. The calculations of the frame, edge-of-glass, divider, and divider edge U-values is discussed in Section 6.

\subsubsection{Window Solar Heat Gain Coefficient}

The total Solar Heat Gain Coefficient is determined by an area weighted average of contributions from the transparent and the opaque elements in the window. The entire vision area is multiplied by the center-ofglass Solar Heat Gain Coefficient, see Section 5.2.3. Determination of the SHGC of opaque window components and the total SHGC is discussed in this section.

\section{Solar Heat Gain Coefficient of Opaque Window Components}

The Solar Heat Gain Coefficient, SHGC, is a function of the solar transmittance, the solar absorptances of each layer and the inward flowing fraction of thermal energy. The SHGC is calculated for each component of the window separately and takes the general form:

SHGC $=\mathrm{T}^{\mathrm{sol}}+\mathrm{A}^{\mathrm{sol}} \mathrm{N}$

Where $T^{\text {sol }}$ is the solar transmittance, $A^{\text {sol }}$ is the solar absorptance and $\mathrm{N}$ is the inward flowing fraction. For the opaque components of the window, frame elements and dividers, $\mathrm{T}^{\mathrm{sol}}=0$ and $\mathrm{Eq} .2 .2 .2 \mathrm{a}$ reduces to the product of the solar absorptance and the inward flowing fraction. The inward flowing fraction for the opaque components, $\mathrm{N}_{\mathrm{opq}}$, is the U-Value of the component, $\mathrm{U}_{\mathrm{opq}}$, divided by the external convective film coefficient, hc out:

$\mathrm{SHGC}_{\text {opq }}=\mathrm{A}_{\mathrm{opq}}^{\text {sol }} \mathrm{N}_{\text {opq }}=\mathrm{A}_{\text {opq }}^{\text {sol }} U_{\text {opq }} / \mathrm{hc}_{\text {out }}$

where $U_{\text {opq }}$ is the area weighted average of the $U$-values of the opaque elements of the window:

$A_{\text {opq }}^{\text {sol }} U_{\text {opq }}=\left(\sum_{i} A_{F_{i}}^{\text {sol }} U_{F_{i}} A_{F_{i}}+\sum_{j} A_{D_{j}}^{\text {sol }} U_{D_{j}} A_{D_{j}}\right) /\left(\sum_{i} A_{F_{i}}+\sum_{j} A_{D_{j}}\right)$

The solar absorbtances $\mathrm{A}_{\mathrm{F}}^{\mathrm{sol}}$ and $\mathrm{A}_{\mathrm{D}}^{\text {sol }}$, are found in the FRAME LIBRARY and the DIVIDER LIBRARY. For more information on the general calculation of the inward flowing fraction see Section 5.2.

\section{Total Solar Heat Gain Coefficient}

All the transparent regions, center-of-glass, edge-of-glass, and divider edge, have the same SHGC. Once the SHGC of the opaque elements is determined the total Solar Heat Gain Coefficient is calculated as the area weighted average of the SHGC through the transparent and the opaque portions of the window: 
$\operatorname{SHGC}_{\text {TOT }}=\left(\sum_{j} \mathrm{SHGC}_{\mathrm{C}_{j}} \times \mathrm{A}_{\mathrm{VIS}_{j}}+\mathrm{SHGC}_{\mathrm{D}_{j}} \times \mathrm{A}_{\mathrm{D}_{j}}+\sum_{\mathrm{i}} \mathrm{SHGC}_{\mathrm{F}_{\mathrm{i}}} \times \mathrm{A}_{\mathrm{F}_{\mathrm{i}}}\right) / \mathrm{A}_{\text {TOT }}$

\subsubsection{Window Shading Coefficient}

The Shading Coefficient, SC, is calculated by dividing the total Solar Heat Gain Coefficient by the Solar Heat Gain Coefficient for double strength glass. WINDOW 4.0 uses the value of the Solar Heat Gain Coefficient for double strength glass based on the spectral calculation using an air mass of 1.5, see Section 8.2. This value of the solar heat gain coefficient is 0.86 which differs from the value of 0.87 (determined using an old air mass 2.0) which is sometimes used in calculating the Shading Coefficient [ASHRAE, 1989].

$\mathrm{SC}=\mathrm{SHGC} / 0.86$

\subsubsection{Window Visible Transmittance}

The visible transmittance of the window is obtained by multiplying the center-of-glass transmittance, see Section 5.2.4, by the ratio of the vision area to the total area:

Tvis $=\sum_{j}$ Tvis $_{C_{j}} \times A_{V} s_{j} / A_{\text {TOT }}$

\subsection{Combination Windows}

The total properties of combination windows are calculated by multiplying the total window properties of each window making up the combination by their respective areas. These weighted properties are then summed and divided by the projected area of the combination window. The combination window option allows the user to design nonplanar windows, such as greenhouse windows. In the case of nonplanar windows the user inputs a value for the projected area of the total combination window. The projected area is defined as the rough opening less the installation clearances. This area may be different than the sum of the areas of the windows that make up the combination.

\subsection{GLASS LIBRARY}

The thermal and optical properties of single layers of glazing material are stored in the GLASS LIBRARY. In earlier versions of the program, only one value for each optical property of a glazing layer is used. This is referred to as a single band model. In a single band model it is assumed that the average value over the entire wavelength spectrum is the value at each wavelength. WINDOW 4.0 introduces a multi-band spectral model. In order to utilize the multi-band model, spectral data for the glazing layer must be available. This spectral data includes values for the transmittance, and reflectance of the front and back surfaces. The properties are recorded as direct normal values. The values for the infrared transmittance and hemispherical emittance are either provided in the spectral data file or calculated by the program. The solar, visible, and infrared optical properties are normalized weighted averages. Each of these averages is based on a different weighting function and wavelength range. The averages are calculated using a numerical integration. The method used to calculate the optical properties of single glazing layers is the same as is used with glazing systems made up of multiple layers. The method for determining the overall spectral transmittance and reflectances of multiple layer glazing systems is discussed in Section 7.1.1. For 
glazing systems with multiple layers, the optical properties for the total glazing system are calculated at each wavelength, and these values are integrated to obtain the various averages. In addition to the optical properties stored in the GLASS LIBRARY is an important thermal property, the thermal conductivity. The value of the thermal conductivity, in general, is a measured property and is not calculated within WINDOW 4.0. The values of the thermal conductivity of the laminated glass products included in WINDOW 4.0 are calculated using the properties of the individual layers. The calculation method used to determine the thermal conductivity of laminated glass products is also included this section.

\subsection{Calculation of Average Optical Properties}

The values of the total optical properties displayed in the GLASS LIBRARY are normalized weighted averages calculated by the following integration:

$$
P_{x}=\int_{a}^{b} P(\lambda) E_{x}(\lambda) \Gamma_{x}(\lambda) d \lambda / \int_{a}^{b} E_{x}(\lambda) \Gamma_{x}(\lambda) d \lambda
$$

Where $P$ is the property; the subscript, $x$, indicates whether the average is taken over the visible, solar or infrared portion of the spectrum; $P(\lambda)$ are the wavelength dependent values of the property found in the spectral data file; $E$ is the spectral weighting function; $\Gamma$ is the auxiliary function (unity except for the visible calculation); and $a$ and $b$ are the lower and upper wavelength limits. See Table 3.1 for the values of $\mathrm{P}, \mathrm{x}, \mathrm{E}, \Gamma, \mathrm{a}$, and $\mathrm{b}$ used in conjunction with Eq. 3.1 to calculate the optical properties.

\begin{tabular}{|l|l|l|l|l|l|}
\hline $\begin{array}{l}\text { x } \\
\text { Property } \\
\text { Classification }\end{array}$ & $\begin{array}{l}\text { P } \\
\text { Property }\end{array}$ & $\begin{array}{l}\text { a Lower } \\
\text { Wavelength } \\
\text { (microns) }\end{array}$ & $\begin{array}{l}\text { b Upper } \\
\text { Wavelength } \\
\text { (microns) }\end{array}$ & $\begin{array}{l}\text { E }_{\mathrm{x}} \text { Spectral } \\
\text { Weighting Function }\end{array}$ & $\begin{array}{l}\Gamma_{\mathrm{x}} \text { Auxiliary } \\
\text { Function }\end{array}$ \\
\hline Solar & $\begin{array}{l}\text { Transmittance } \\
\text { Reflectances } \\
\text { Absorptance }\end{array}$ & $0.32^{1}$ & 2.5 & Solspect.dat ${ }^{2}$ & 1.0 \\
\hline Visible & $\begin{array}{l}\text { Transmittance } \\
\text { Reflectance }\end{array}$ & 0.32 & 0.78 & Solspect.dat & CIE31t.dat $^{3}$ \\
\hline IR & $\begin{array}{l}\text { Transmittance } \\
\text { Reflectances }\end{array}$ & 5.0 & 50.0 & Planck's Function & 1.0 \\
\hline
\end{tabular}

Table 3.1 Values used the Eq. 3.1

\section{Notes for Table 3.1}

1. If data is not available at $0.32 \mu \mathrm{m}$, WINDOW will extrapolate data from $0.35 \mu \mathrm{m}$, or the lowest value, to a value of 0 at $0.32 \mu \mathrm{m}$. If the data is not presented out to $2.5 \mu \mathrm{m}$, the last input value (as long as it is at least at 2.0 microns) is used at the value at $2.5 \mu \mathrm{m}$ also.

2. Solar weighting function found in ASTM E-891 1987, Table 1, using an Air Mass of 1.5.

3. Tristimulus values for the $2^{\circ}$ observer as found in the CIE 1931 Standard. The values for $\bar{y}$ as given in ASTM E308 1990, Table 1 are used as the auxiliary function.

4. Planck's function (Siegal and Howell, 1981): $\quad E(\lambda)=2 \pi c_{1} \lambda^{-5}\left(\exp \left(c_{2} / \lambda \Theta\right)-1\right)^{-1}$

Where $c_{1}=.59544 \times 10^{8} \mathrm{~W} \mu \mathrm{m}^{4} / \mathrm{m}^{2}, c_{2}=14388 \mu \mathrm{mK}, \Theta=300 \mathrm{~K}$ and $\lambda$ is measured in microns. For the Infrared integration, Planck's function is evaluated at $1 \mu \mathrm{m}$ intervals. 


\subsubsection{Numgrical Integration of Spectral Integral}

Equation 3.1 is evaluated by converting the continuous integral into a summation of discrete values. The value of the functions $P_{x}(\lambda) E_{x}(\lambda) \Gamma_{x}(\lambda)$ and $E_{x}(\lambda) \Gamma_{x}(\lambda)$ are evaluated at every wavelength value given for the weighting function $E_{x}(\lambda)$. If values for $P_{x}$ or $\Gamma_{x}$ are not available for the wavelengths at which $E_{x}$ is evaluated, then a linear interpolation is performed on $P_{x}$ or $\Gamma_{x}$ to obtain the missing values. The trapezoid rule is used to evaluate Eq. 3.1. The trapezoid rule assumes that the function to be integrated varies linearly between adjacent wavelength values, see Fig. 3.1. This is equivalent to the assumption that the average value between two adjacent wavelengths is the value over the entire wavelength interval. The endpoints are not treated any differently than the internal points. The discretized integral, for any function $f(\lambda)$, takes the following form:

$\int_{a}^{b} f(\lambda) d \lambda=0.5 \times\left\{\left(f(a)+f\left(\lambda_{2}\right)\right) d \lambda_{1}+\ldots+\left(f\left(\lambda_{i}\right)+f\left(\lambda_{i+1}\right)\right) d \lambda_{i}+\ldots+\left(f\left(\lambda_{N-1}\right)+f(b)\right) d \lambda_{N-1}\right\}$

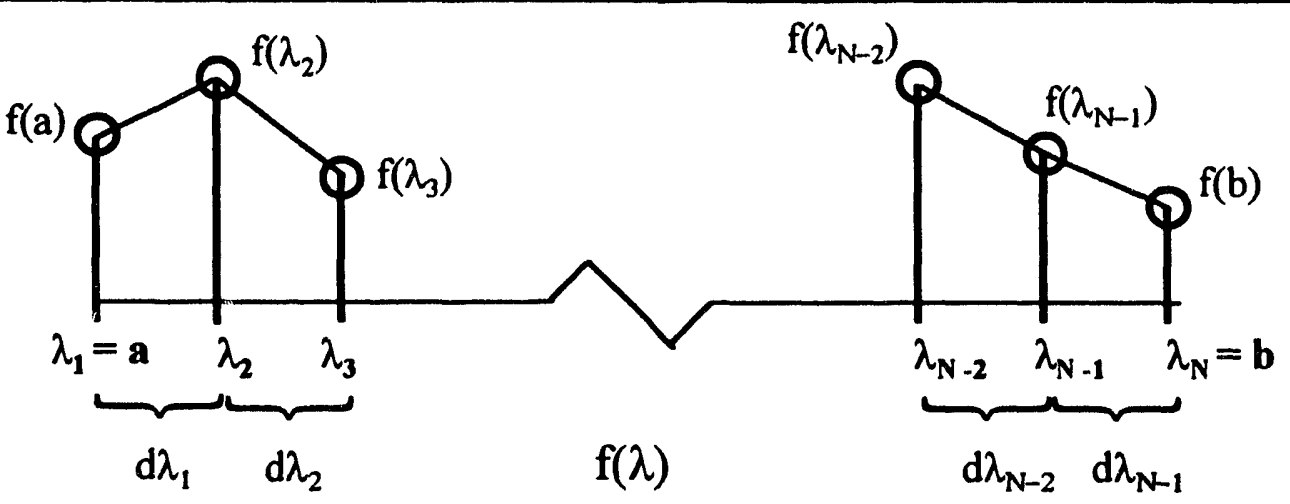

Figure 3.1 Schematic of numerical integration using the trapezoid rule. The dummy function, $f(\lambda)$ is integrated between the limits: $\lambda_{1}=a$ and $\lambda_{2}=N$.

\subsection{Calculation of Hemispherical Emittance}

The normal infrared emissivities are calculated from the normal infrared reflectivities by using the equation $\varepsilon=1-\rho$. The hemispherical values of the emissivity, $\varepsilon_{\cap}$, are determined using a polynomial correlation [Rubin, 1987]. The calculation method used to determine all other hemispherical optical properties is discussed in Section 7.3.

If $\varepsilon \leq .65$ the glass is considered to be coated and the following expression is used to calculate the hemispherical emissivity.

$\varepsilon_{n}=1.3217 \varepsilon-1.8766 \varepsilon^{2}+4.6586 \varepsilon^{3}-5.8349 \varepsilon^{4}+2.7406 \varepsilon^{5}$

If $\varepsilon>.65$ the glass is considered to be uncoated and the following expression is used to calculate the hemispherical emissivity.

$\varepsilon_{\cap}=0.1569 \varepsilon+3.7669 \varepsilon^{2}-5.4398 \varepsilon^{3}+2.4733 \varepsilon^{4}$ 


\subsection{Thermal Conductivity of Laminated Glass Products}

The values for the thermal conductivity of the laminated glass products that are included in WINDOW 4.0 have been determined as follows:

$k=\frac{t_{\text {glass }}+t_{P V B}+t_{\text {glass }}}{t_{\text {glass }} / k_{\text {glass }}+t_{P V B} / k_{P V B}+t_{\text {glass }} / k_{\text {glass }}}$

All the laminated glass products included in the program are made up of single layers of polyvinyl butyral sandwiched between two pieces of glass.

\subsection{GAS LIBRARY}

The GAS LIBRARY displays properties of gases that can be used as fills in glazing systems. The user has a choice of air, argon, krypton, $\mathrm{CO}_{2}, \mathrm{SF}_{6}$ and any fractional combinations of air/argon/krypton or any fractional combinations of argon and $\mathrm{SF}_{6}$. The values of the properties displayed in the GAS LIBRARY are used to calculate the gap film coefficient, see Section 8.2.5. The information in this section has been previously documented, [Arasteh 1989b] and is included here for completeness.

\begin{tabular}{|c|c|c|c|c|c|c|c|c|}
\hline Gas & $\begin{array}{l}\mathbf{k} \\
\mathrm{W} / \mathrm{m}-\mathrm{K}\end{array}$ & $\begin{array}{l}\mathbf{d k} / \mathbf{d T} \\
\mathrm{W} / \mathrm{m}-\mathrm{K}^{2} \\
\times 10^{-5}\end{array}$ & $\begin{array}{l}\mu \\
\mathrm{kg} / \mathrm{m}-\mathrm{s} \\
\times 10^{-5}\end{array}$ & $\begin{array}{l}\mathrm{d} \mu / \mathrm{dT} \\
\mathrm{kg} / \mathrm{m}-\mathrm{s}-\mathrm{K} \\
\times 10^{-8}\end{array}$ & $\begin{array}{l}\boldsymbol{\rho} \\
\mathrm{kg} / \mathrm{m}^{3}\end{array}$ & $\begin{array}{l}\mathrm{d \rho} / \mathrm{dT} \\
\mathrm{kg} / \mathrm{m}^{3}-\mathrm{K}\end{array}$ & $\mathbf{P r}$ & $\begin{array}{l}\mathrm{dPr} / \mathrm{dT} \\
\mathrm{l} / \mathrm{K}\end{array}$ \\
\hline Air & 0.0241 & 7.6000 & 1.7300 & 10.0000 & 1.290 & -0.0044 & 0.720 & 0.00180 \\
\hline Argon & 0.0162 & 5.0000 & 2.1100 & 6.3000 & 1.780 & -0.0060 & 0.680 & 0.00066 \\
\hline Krypton & 0.0086 & 2.8000 & 2.2800 & 7.5000 & 3.740 & -0.0137 & 0.660 & 0.00002 \\
\hline $\mathrm{CO}_{2}$ & 0.0146 & 7.4000 & 1.3900 & 5.0000 & 1.980 & 0.0000 & 0.790 & 0.00130 \\
\hline $\mathrm{SF}_{6}$ & 0.0130 & 7.1000 & 1.4100 & 4.0000 & 6.600 & -0.0240 & 0.690 & 0.00270 \\
\hline
\end{tabular}

Table 4.1 Thermal properties of pure gases given in the GAS LIBRARY of WINDOW 4.0

The values of the thermal properties for the pure gases: Air, Argon, Krypton, $\mathrm{CO}_{2}$ and $\mathrm{SF}_{6}$ are shown in Table 4.1 as they appear in WINDOW 4.0. [NOTE: The value for the density of Argon in WINDOW 4.0 is corrected from the density value of 1.70 used in WINDOW 3.1. The values displayed in IP units for the temperature derivative of the Prandtl Number, dPr/dT, in WINDOW 3.1 are incorrect. This did not effect the calculation, however, because all calculations are done in SI units. The values of $\mathrm{dPr} / \mathrm{dT}$ in IP units are displayed correctly in WINDOW 4.0.]

\subsection{Calculations of Properties of Gas Mixtures}

The properties of gas mixtures are determined from polynomial expressions. The coefficients of these expressions were obtained using a chemical kinetics program [Kee, 1983]. The thermophysical properties (P) of Air/ $\mathrm{Ar} / \mathrm{Kr}$ and $\mathrm{Ar} / \mathrm{SF}_{6}$ mixtures were determined. These are expressed as:

$\mathrm{P}\left(\chi_{\mathrm{air},}, \chi_{\mathrm{ar},}, \chi_{\mathrm{kr}}\right)=\mathrm{A}_{1}+\mathrm{A}_{2} \chi_{\mathrm{air}}+\mathrm{A}_{3} \chi_{\mathrm{air}}^{2}+\mathrm{A}_{4} \chi_{\mathrm{ar}}+\mathrm{A}_{5} \chi_{\mathrm{ar}}^{2}+\mathrm{A}_{6} \chi_{\mathrm{kr}}+\mathrm{A}_{7} \chi_{\mathrm{kr}}^{2}$

and

$$
\mathrm{P}\left(\chi_{\mathrm{ar},} \chi_{\mathrm{SF}_{6}}\right)=\mathrm{B}_{1}+\mathrm{B}_{2} \chi_{\mathrm{ar}}+\mathrm{B}_{3} \chi_{\mathrm{ar}}^{2}
$$


where

$\chi_{\text {air }}=$ volumetric fraction of air

$\chi_{\mathrm{ar}}=$ volumetric fraction of argon

$\chi_{\mathrm{kr}}=$ volumetric fraction of krypton

$\chi_{\mathrm{SF}_{6}}=$ volumetric fraction of sulfur hexaflouride

The values for A and B are listed in Tables 4.2 and 4.3.

\begin{tabular}{|l|l|l|l|l|l|l|l|}
\hline $\mathbf{P}$ & $\mathbf{A}_{\mathbf{1}}$ & $\mathbf{A}_{2}$ & $\mathbf{A}_{3}$ & $\mathbf{A}_{4}$ & $\mathbf{A}_{5}$ & $\mathbf{A}_{6}$ & $\mathbf{A}_{7}$ \\
\hline $\boldsymbol{\lambda} \times 10^{2}$ & 0.857 & 1.438 & 0.0957 & 0.897 & -0.079 & -0.272 & 0.282 \\
\hline $\mathbf{d} \lambda / \mathbf{d T} \times \mathbf{1 0}^{5}$ & 2.123 & 4.969 & -0.235 & 2.723 & 0.406 & 0.813 & -0.157 \\
\hline $\boldsymbol{\mu} \times 10^{5}$ & 1.061 & 0.855 & -0.166 & 0.958 & 0.131 & 1.580 & -0.335 \\
\hline $\mathbf{d} \boldsymbol{\mu} / \mathbf{d T} \times \mathbf{1 0}^{7}$ & 0.280 & 0.280 & -0.066 & 0.341 & 0.046 & 0.676 & -0.170 \\
\hline$\rho$ & 0 & 1.29 & 0 & 1.78 & 0 & 3.74 & 0 \\
\hline $\mathbf{d} \rho / d T \times \mathbf{1 0}^{3}$ & 0 & -4.4 & 0 & -6.0 & 0 & -13.7 & 0 \\
\hline $\mathbf{P r}$ & 0 & 0.72 & 0 & 0.68 & 0 & 0.66 & 0 \\
\hline $\mathbf{d P r} / \mathbf{d T} \times \mathbf{1 0}^{3}$ & 0 & 1.8 & 0 & 0.66 & 0 & 0.02 & 0 \\
\hline
\end{tabular}

Table 4.2 Coefficients for Use in Eq. $4.1 \mathrm{a}$

\begin{tabular}{|l|l|l|l|}
\hline$P$ & $B_{1}$ & $B_{2}$ & $B_{3}$ \\
\hline$\lambda \times 10^{2}$ & 1.303 & 0.153 & 0.212 \\
\hline$d \lambda / \mathbf{d T} \times 10^{5}$ & 7.1 & -2.1 & 0 \\
\hline$\mu \times 10^{5}$ & 1.417 & 0.197 & 0.520 \\
\hline$d \mu / d T \times 10^{7}$ & 0.4 & 0.2 & 0 \\
\hline$\rho$ & 6.600 & -4.900 & 0 \\
\hline$d \rho / d T$ & -24.0 & 18.0 & 0 \\
\hline$P r$ & 0.69 & -0.01 & 0 \\
\hline dPr/dT & 2.70 & -2.03 & 0 \\
\hline
\end{tabular}

Table 4.3 Coefficients for Use in Eq. $4.1 \mathrm{~b}$

\subsection{GLAZING SYSTEM LIBRARY}

The GLAZING SYSTEM LIBRARY is a screen for creating glazing systems. Longtime users will notice its similarity to the main screen of previous versions. The center-of-glass performance indices, $U$-value $\left(U_{C}\right)$, Solar Heat Gain Coefficient $\left(\mathrm{SHGC}_{\mathrm{C}}\right)$, Shading Coefficient $\left(\mathrm{SC}_{\mathrm{C}}\right)$, Visible transmittance $\left(\mathrm{Vt}_{\mathrm{C}}\right)$, and Relative Heat Gain (RHG) are displayed on this screen. These indices are calculated using the results displayed on the OPTICAL PROPERTIES and TEMPERATURE SCREEN. This section presents the final calculations and references the sections where the intermediate steps are found. In general the optical properties are discussed in Section 7 and the determination of the steady state temperature profile is discussed in Section 8. The value of the effective conductivity, KEFF, of the glazing layer is discussed in this section.

\subsection{Center of Glass U-value}

The center-of-glass U-value is the inverse of the sum of the thermal resistance between each pair of adjacent nodes in the glazing system, see Fig. 8.1. The thermal resistances are determined (see Section 
8.2.6) once the steady state temperature profile across the glazing system is known. Nodes are located at the midpoint and surfaces of each glazing layer. The resistance between each node is the inverse of the conductance. This conductance is influenced by three modes of heat transfer: conduction, convection and radiation. The $U$-value is a measure of the overall conductance of thermal energy.

$\mathrm{U}_{\mathrm{C}}=1 / \sum_{\mathrm{j}=1}^{\mathrm{N}} \mathbf{R}_{\mathrm{j}}$

\subsection{Center of Glass Solar Heat Gain Coefficient}

The SHGC is a function of the total solar transmittance of the glazing system, see Section 7.2.1, the inward flowing fraction of absorbed solar energy and the absorptance of each layer, see Section 7.2.2:

$$
\text { SHGC }_{C}=T_{1, N}^{\text {sol }}+\sum_{j=1}^{N} N_{j} A_{j}^{\text {sol }}
$$

Where $\mathbf{N}_{\mathrm{j}}$, the inward flowing fraction of absorbed solar energy is defined as the sum of the resistances up to a given node divided by the sum of all the resistances.

$$
N_{j}=\sum_{m=1}^{j-1} R_{m} / \sum_{j=1}^{N} R_{j}
$$

\subsection{Center-of-Glass Shading Coefficient}

The center-of-glass Shading Coefficient is determined by dividing the center-of-glass Solar Heat Gain Coefficient by the value of the Solar Heat Gain Coefficient of double strength, $3 \mathrm{~mm}$, clear glass. In WINDOW 4.0 the SHGC $_{C}$ of double strength glass has a value of 0.86 .

\subsection{Center of Glass Visible Transmittance}

The calculation of this index is discussed in Section 7.1.1.

\subsection{Relative Heat Gain}

The Relative Heat Gain, RHG, is an index that is only associated with the glazing system and has no total window counterpart. The Relative Heat Gain is calculated as follows [ASHRAE, 1989]:

$$
\mathrm{RHG}=\mathrm{SC}_{\mathrm{C}} \times 631 \mathrm{~W} / \mathrm{m}^{2}+7.78^{\circ} \mathrm{C} \times \mathrm{U}_{\mathrm{C}}
$$

\subsection{Effective Conductivity for Gas Cavities}

The Effective Conductivity, KEFF, is an approximate value that incorporates the convection and radiation heat transfer effects into an equivalent conductance. This approximation allows the complex heat transfer across the gap to be treated as simple conduction by the FRAME program (Enermodal Engineering, 1991). The value of the Effective Conductivity is determined after the window temperature profile and the centerof-glass U-Value are known. The overall heat transfer, $Q_{C}$, through the center-of-glass is the product of the center-of-glass U-value and the temperature difference of the two outermost glass faces. KEFF is then 
determined using the known temperature difference across the glazing system gap and the thickness of the gap.

$$
\mathrm{Q}_{\mathrm{C}}=\mathrm{U}_{\mathrm{C}}\left(\theta_{\mathrm{sl}}-\theta_{\mathrm{s} 2 \mathrm{~N}}\right)
$$

and

$$
\operatorname{KEFF}=\left(Q_{C} \times \omega\right) /\left(\theta_{\mathrm{s} 2}-\theta_{\mathrm{s} 2 \mathrm{~N}-1}\right)
$$

In the equations above the subscript $\mathbf{N}$ indicates the number of glazing layers in the glazing system and $\theta_{s}$ is the surface temperature. The numerical subscripts of $\theta_{s}$ indicate the surface of the glazing layer where 1 is the outermost surface and $2 \mathrm{~N}$ is the inward facing surface, see Fig. 8.1. The width of the gap, $\omega$, is the thickness of the total gap measured from the inward facing surface of the outermost layer to the outward facing surface of the innermost layer. The gap thickness is filled with gas in a two layer glazing system and with a combination of gas and glazing if the glazing system has more than 2 layers. KEFF is not defined for a single layer glazing system.

\subsection{FRAME/DIVIDER LIBRARY}

The FRAME and the DIVIDER LIBRARY have a similar structure and are discussed together. The FRAME LIBRARY lists frame elements: the header; jambs; sill and meeting rail (check rail, interlock, mullion) for use on the Main Screen, see Section 2.2. The FRAME LIBRARY contains information necessary for calculating thermal performance; frame and edge U-values, absorptance and projected frame dimension. Three different "Sources" or types of frame records can be used in the FRAME LIBRARY: ASHRAE/LBL, Generic, and FRAME 3.0. The DIVIDER LIBRARY lists grilles, muntins and other divider elements along with their associated divider and divider edge properties for use on the MAIN SCREEN. The DIVIDER LIBRARY contains information necessary for calculating thermal performance: divider and divider edge Uvalues, absorptance, and projected divider dimension. Three different "Sources" or types of divider records can provide these properties to the DIVIDER LIBRARY: LBL, Generic and FRAME 3.0. The calculations related to each of the different "Sources" for both frames and dividers are discussed in this section.

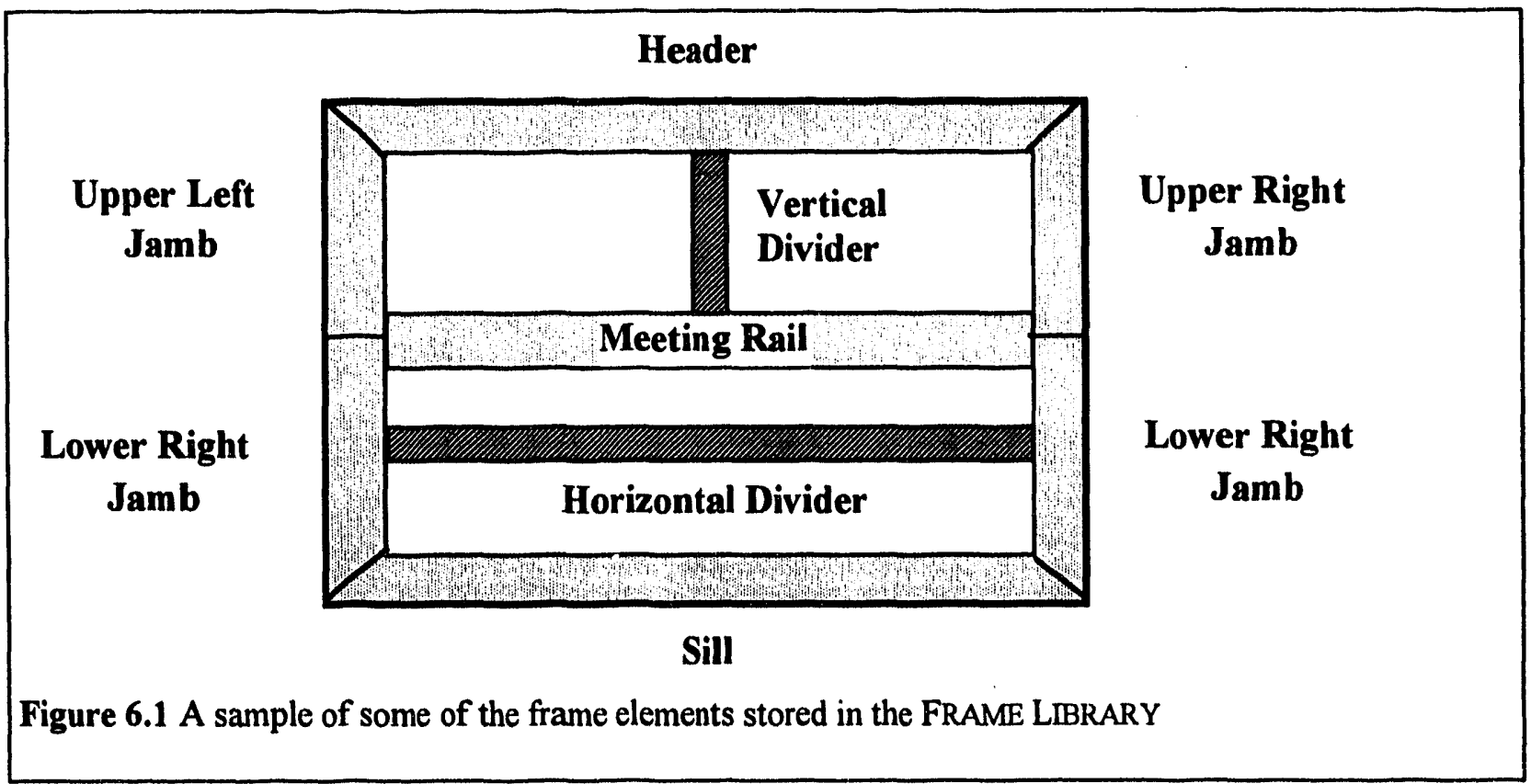




\subsection{ASHRAE/LBL Frames}

The default FRAME LIBRARY includes five records representing the frame $\mathrm{U}$-values that were determined for ASHRAE [1989] and utilized in WINDOW 3.1. These five entries are referred to as "ASHRAE/LBL." The value of the solar absorption of the frame is used to calculate the Solar Heat Gain Coefficient of the opaque elements of the window, see Section 2.2.2. The projected frame dimension, is the width of the frame element in the plane of the glazing and is used to calculate the frame area, see Section 2.1.1. In this report the variable, $w$, is used to represent the projected frame and projected divider dimensions. Edge Uvalue correlations are provided for ASHRAE/LBL frames. Details on the derivation of these correlations can be found in Arasteh [1989a]. The spacer/edge systems modeled by these correlations were chosen to represent a range from the highly conductive to the highly insulating.

\subsubsection{The Edge U-value}

For ASHRAE/LBL frames the edge U-value is treated as a function of the spacer type and the center-ofglass U-value. The general polynomial representing this functionality is as follows:

$\mathrm{U}_{\mathrm{E}}=\mathrm{A}_{1}+\mathrm{A}_{2}\left(\mathrm{U}_{\mathrm{C}}\right)+\mathrm{A}_{3}\left(\mathrm{U}_{\mathrm{C}}\right)^{2}$

The values of the coefficients are dependent on the spacer material, see Table 6.1. All coefficients are given in SI units. [NOTE: Some of these values are different than those used in WINDOW 3.1.]

\begin{tabular}{|l|l|l|l|l|l|}
\hline Corr. \# & Spacer Type & Al & A2 & A3 & Source \\
\hline 1 & Aluminum ASHRAE Metallic & 2.33 & -0.01 & 0.138 & ASHRAE \\
\hline 2 & Stainless Steel; dual steel & 1.03 & 0.76 & 0.0085 & Arasteh, 1989 \\
\hline 3 & Butyl/Metal (Fiberglass, Wood, Glass Edge) & 0.82 & 0.80 & 0.0022 & Arasteh, 1989 \\
\hline 4 & Insulated & 0.35 & 0.83 & 0.018 & Arasteh, 1989 \\
\hline 5 & $\mathrm{U}_{\mathrm{E}}=\mathrm{U}_{\mathrm{C}}$ & 0.00 & 1.00 & 0.00 & \\
\hline
\end{tabular}

Table 6.1 Coefficients used to calculate edge-of-glass U-values

\subsection{Generic Frames}

The thermal properties of Generic Frames are input interactively into the Frame Library. There are two types of Generic Frames: a modified ASHRAE/LBL frame or a user specified frame. The frame U-value, absorptance, and PFD of Generic frames must be supplied by the user. The edge U-value can be specified in two ways. The user can either input a single value or use one of the edge $U$-value correlations discussed in Section 6.1.1.

\subsection{FRAME 3.0 Frames}

The third "source" of frame data is the FRAME program [Enermodal Engineering, 1991]. WINDOW and FRAME 3.0 can be used together to model total window thermal and optical performance. To perform this modeling, first glazing systems are modeled in WINDOW and stored in the GLAZING SYSTEM LIBRARY. Then FRAME imports the GLAZING SYSTEM LIBRARY and in conjunction with a geometric representation of frame cross-sections performs a two-dimensional heat transfer analysis. FRAME can simulate the thermal performance of a frame/edge system for one specific glazing system, for two related glazing systems or for four related glazing systems. A detailed description of the various simulation types is given by Beck [1993]. The simulations that use multiple glazing systems allow for greater flexibility when modeling total window systems in WINDOW. The accuracy of modeling thermal behavior of windows 
using these multiple glazing system simulations has been validated [Beck, 1993]. Upon completion of the FRAME simulation a converged file containing the information needed for the FRAME LIBRARY in WINDOW is created. These files have the extension .F30 and must reside in the FRAMEDAT subdirectory to be accessed by WINDOW. Once these file names are entered into the FRAME LBBRARY they are available for use. Glazing systems and frame elements are combined to model total windows on the MAIN SCREEN. The program ensures that the selected glazing system is a good match for the frame elements selected. In WINDOW a "good match" is defined as a glazing system with center-of-glass U. value $\left(U_{C}\right)$ and the glazing system thickness $\left(t_{C}\right)$, within a tolerance (tol) of $\pm 5 \%$ of the glazing system properties used in the FRAME simulation. This section describes the tolerance determination for each of the simulation types. The interpolation schemes used by WINDOW to combine glazing systems and data from *.F30 files for each simulation type into total window models is also described.

\subsubsection{One Glazing System Simulation - Type I}

FRAME's basic and most frequently used mode is to model frame and edge U-values for a specific glazing system. For this type of model the FRAME LIBRARY displays the frame and edge U-value, the glazing width and center-of-glass $U$-value, the projected frame dimension, and the absorptance. WINDOW requires that the center-of-glass $U$-value $\left(U_{C}\right)$ and the glazing system thickness $\left(t_{c}\right)$, fall within a tolerance (tol) of $\pm 5 \%$ of the glazing system properties used in the simulation.

$$
\begin{aligned}
& (1-\mathrm{tol}) \times \stackrel{?}{\mathrm{t}^{\prime}} \leq \stackrel{?}{\leq} \mathrm{t}_{\mathrm{C}} \leq(1+\mathrm{tol}) \times \mathrm{t}^{\prime} \\
& (1-\mathrm{tol}) \times \stackrel{?}{\mathrm{U}^{\prime}} \stackrel{?}{\leq} \mathrm{U}_{\mathrm{C}} \stackrel{?}{\leq}(1+\mathrm{tol}) \times \mathrm{U}^{\prime}
\end{aligned}
$$

For a Type 1 simulation this tolerance calculated around a single point with a primary glazing system having a $U$-value of $U^{\prime}$ and a thickness of $t^{\prime}$. Acceptable glazing systems have $U_{c}$ and $t_{c}$ that fall within a rectangular region denoted by the shaded area in Fig. 6.2. If the selected glazing system does not meet the tolerance criterion WINDOW issues a warning message and the calculation is aborted. The Type I simulation is used in WINDOW without any interpolation.

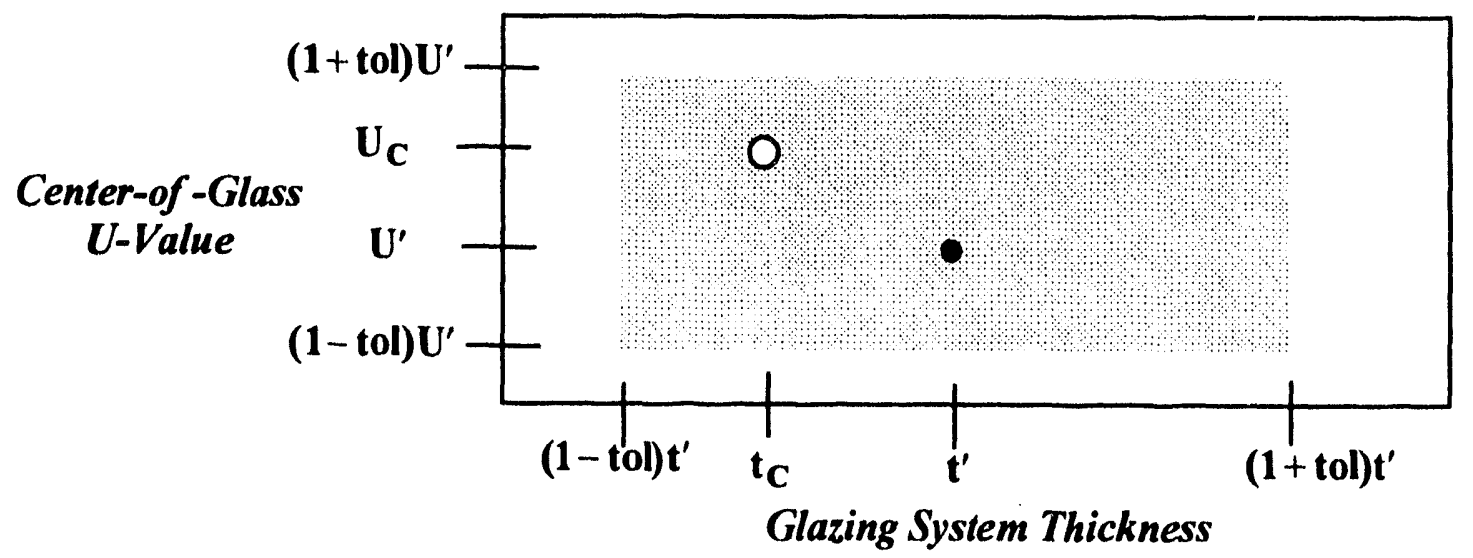

Figure .6.2 Tolerance criterion for a Type I Simulation. The shaded area denotes the region of acceptable combinations of $U_{C}$ and $t_{C}$. The black dot indicates the properties of the glazing system used in the FRAME simulation. The white dot indicates the properties of a glazing system that could be combined with this *.F30 file to create a total window. 


\subsubsection{Two Glazing System Simulations - Type II and III}

The frame and edge U-values can be modeled for two different glazing systems. The Type II simulation uses two glazing systems with equal widths but different center-of-glass properties. These glazing systems are referred to as the primary glazing system with properties, $U^{\prime}$ and $t^{\prime}$, and the alternate primary glazing system with properties, $U_{\text {alt }}^{\prime}$ and $t_{\text {alt }}^{\prime}$. The Type III simulation uses two glazing systems with equal centerof-glass U-values but different widths. These glazing systems are referred to as the primary glazing system with properties, $U^{\prime}$ and $t^{\prime}$, and the secondary glazing system with properties, $U^{\prime \prime}$ and $t^{\prime \prime}$. The advantage of Type II and Type III simulations is that a greater range of glazing systems can be used with each FRAME file when modeling windows.

\section{Type II}

For this type of model the FRAME LIBRARY displays the width of the glazing systems, the projected frame dimension and the absorptance of the frame. As with the Type I frames, the program tests to see if the selected glazing system is compatible with the modeled frame. The glazing system thickness, $t_{c}$, is tested using Eq. 6.3.1a. The glazing system center-of-glass $U$-value, $U_{C}$, is tested in relation to the two glazing systems used to create the simulation:

$$
(1-\text { tol }) \times U^{\prime} \stackrel{?}{\leq} U_{\mathrm{C}} \stackrel{?}{\leq}(1+\text { tol }) \times U_{\text {alt }}^{\prime}
$$

For a Type Il simulation the tolerance is calculated around two points, the primary glazing system having a center-of-glass $U$-value of $U^{\prime}$ and a thickness of $t^{\prime}$ and the alternate primary glazing system having a centerof-glass $U$-value of $U_{\text {alt }}^{\prime}$ and a thickness of $t_{a l t}^{\prime}$. Acceptable glazing systems have $U_{c}$ and $t_{c}$ that fall within a rectangular region denoted by the shaded area in Fig. 6.3. If the selected glazing system does not meet the tolerance criterion WINDOW issues a warning message and the calculation is aborted.

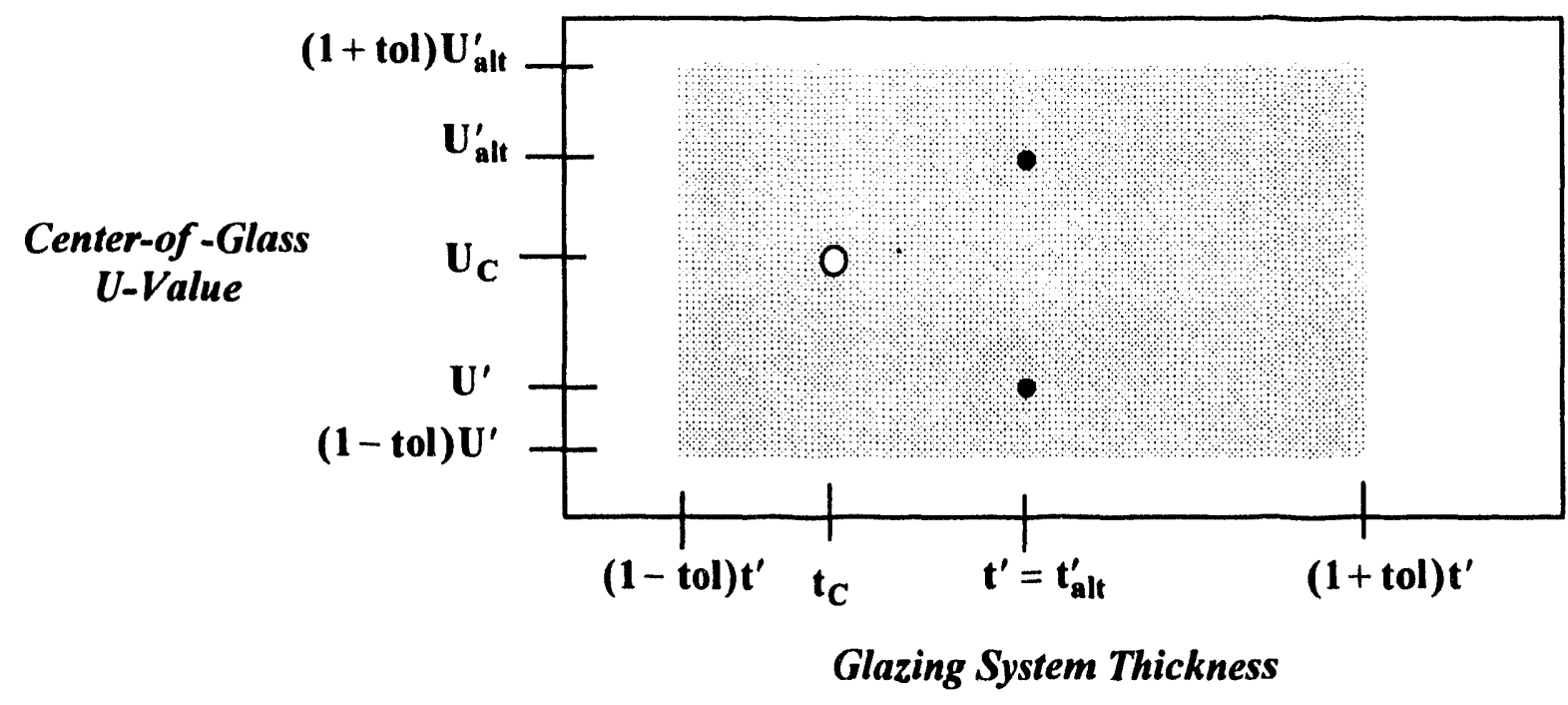

Figure 6.3 Tolerance criterion for a Type II Simulation. The shaded area denotes the region of acceptable combinations of $U_{C}$ and $t_{c}$. The black dots indicate the properties of the glazing systems used in the FRAME simulation. The white dot indicates the properties of a glazing system that could be combined with this *.F30 file to create a total window. 
For Type II simulations the abbreviation "var" appears for the frame, edge and center-of-glass U-values in the FRAME LIBRARY. The frame, $U_{F}$ and edge, $U_{E}, U$-values for the total window are displayed on the Main Screen of WINDOW once an appropriate glazing system has been chosen. These frame and edge-ofglass U-values are determined by linear interpolation within the WINDOW program.

$\mathrm{U}_{\mathrm{F}}=\mathrm{U}_{\mathrm{F}}+\mathrm{R}_{\mathrm{U}} \times\left(\mathrm{U}_{\mathrm{Falt}}-\mathrm{U}_{\mathrm{F}}\right)$

$U_{E}=U_{E}+R_{U} \times\left(U_{E_{\text {alt }}}-U_{E}\right)$

where $R_{U}$ is the $U_{C}$ Ratio: $R_{U}=\frac{U_{C}-U^{\prime}}{U_{\text {alt }}^{\prime}-U^{\prime}}$

Type III

For this type of model the FRAME LBBRARY displays the center-of-glass U-value of the glazing systems, the projected frame dimension and the absorptance of the frame. As with the Type I frame, the program tests to see if the selected glazing system is compatible with the modeled frame. The glazing system U-value, $\mathrm{U}_{\mathrm{C}}$, is tested using Eq. 6.3.1b. The glazing system thickness, $t_{\mathrm{c}}$, is tested in relation to the two glazing systems used to create the simulation.

$$
(1-\mathrm{tol}) \times \mathrm{t}^{\prime} \stackrel{?}{\leq} \mathrm{t}_{\mathrm{C}} \stackrel{?}{\leq}(1+\mathrm{tol}) \times \mathrm{t}^{\prime \prime}
$$

For a Type III simulation the tolerance calculated around two points, the primary glazing system having a center-of-glass $U$-value of $U^{\prime}$ and a thickness of $t^{\prime}$ and the secondary glazing system having a center-ofglass $U$-value of $U^{\prime \prime}$ and a thickness of $t^{\prime \prime}$. Acceptable glazing systems have $U_{c}$ and $t_{c}$ that fall within a rectangular region denoted by the shaded area in Fig. 6.4. If the selected glazing system does not meet the tolerance criterion WINDOW issues a warning message and the calculation is aborted.

Center-of -Glass U-Value

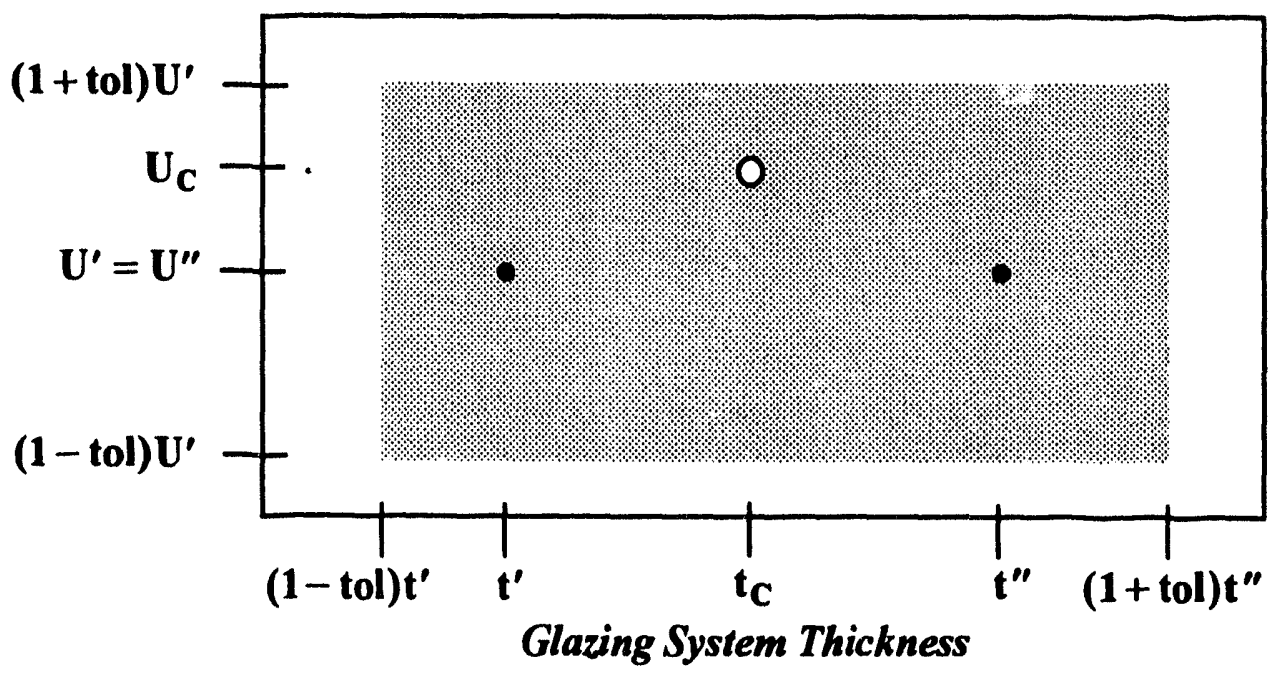

Figure 6.4 Tolerance criterion for a Type III Simulation. The shaded area denotes the region of acceptable combinations of $U_{c}$ and $t_{c}$. The black dots indicate the properties of the glazing systems used in the FRAME simulation. The white dot indicates the properties of a glazing system that could be combined with this *.F30 file to create a total window. 
For Type III simulations the abbreviation "var" appears for the frame, edge and center-of-glass U-values in the FRAME LIBRARY. The frame, $U_{F}$ and edge-of-glass, $U_{E}, U$-values for the total window are displayed on the Main Screen of WINDOW once an appropriate glazing system has been chosen. These frame and edge-of-glass U-values are determined by linear interpolation within the WINDOW program.

$\mathbf{U}_{\mathrm{F}}=\mathbf{U}^{\prime}+\mathbf{R}_{\mathrm{t}} \times\left(\mathbf{U}^{\prime \prime}-\mathrm{U}^{\prime}\right)$

$\mathbf{U}_{\mathrm{E}}=\mathbf{U}^{\prime}+\mathbf{R}_{\mathrm{t}} \times\left(\mathbf{U}^{\prime \prime}-\mathbf{U}^{\prime}\right)$

where $R_{t}$ is the $t_{C}$ Ratio: $R_{t}=\frac{t_{C}-t^{\prime}}{t^{\prime \prime}-t^{\prime}}$

\subsubsection{Four Glazing System Simulation - Type IV}

The frame and edge U-values can be modeled for two sets of glazing systems. These glazing systems are the primary glazing system and the alternate primary glazing system which have the same thickness but different center-of-glass U-values, and the secondary glazing system and alternate secondary glazing system which have the same thickness but different center-of-glass U-values. Using nomenclature consistent with the other simulation types: the primary glazing system has properties, $U^{\prime}$ and $t^{\prime}$; the alternate primary glazing system has properties, $U_{\text {alt }}^{\prime}$ and $t_{a l t}^{\prime}$; the secondary glazing system has properties, $U^{\prime \prime}$ and $t^{\prime \prime}$; and the alternate secondary glazing system has properties, $U_{\text {alt }}^{\prime \prime}$ and $t_{\mathrm{alt}}^{\prime \prime}$. The thicknesses of the primary and secondary glazing systems need not be equal. Type IV frames offer the greatest range of glazing systems that can be used with $a *$.F30 file to model window systems. For this type of model the FRAME LIBRARY displays the projected frame dimension and the absorptance of the frame. The abbreviation "var" appears for the frame, edge-of-glass and center-of-glass U-values and the width of the glazing system. The frame and edge-of-glass U-values are determined by linear interpolation based on both the center-of-glass U-value and the width of the glazing system chosen to be combined with the frame on the MAIN SCREEN.

As with the Type III frame, the program tests to see if the selected glazing system is compatible with the modeled frame. The glazing system thickness, $t_{c}$, is tested using Eq. 6.3.2f. Once the thickness of the glazing system has been verified WINDOW calculates the thickness ratio using Eq. 6.3.2i. Using the thickness ratio, WINDOW then calculates $U_{\max }$ and $U_{\min }$. These values lie on of straight lines connecting the primary and secondary alternate glazing center-of-glass U-values, and the primary and secondary glazing center-of-glass U-values. They are used to calculate the extreme values that of the center-of-glass $U$-value of an acceptable glazing system, $U_{\max }$ and $U_{\min }$, see Fig. 6.5.

$$
\begin{aligned}
& \mathbf{U}_{\max }=\mathbf{U}_{\text {alt }}^{\prime}+\mathbf{R}_{\mathbf{t}} \times\left(\mathbf{U}_{\mathrm{alt}}^{\prime \prime}-\mathbf{U}_{\mathrm{alt}}^{\prime}\right) \\
& \mathbf{U}_{\min }=\mathbf{U}^{\prime}+\mathbf{R}_{\mathbf{t}} \times\left(\mathbf{U}^{\prime \prime}-\mathbf{U}^{\prime}\right)
\end{aligned}
$$

The glazing system center-of-glass $U$-value, $U_{C}$, is tested in relation to these two extreme values.

$$
(1-\text { tol }) \times \mathrm{U}_{\min } \stackrel{?}{\leq} \mathrm{U}_{\mathrm{C}} \stackrel{?}{\leq}(1+\mathrm{tol}) \times \mathrm{U}_{\max }
$$

If the selected glazing system does not meet the tolerance criterion WINDOW issues a warning message and the calculation is aborted. 


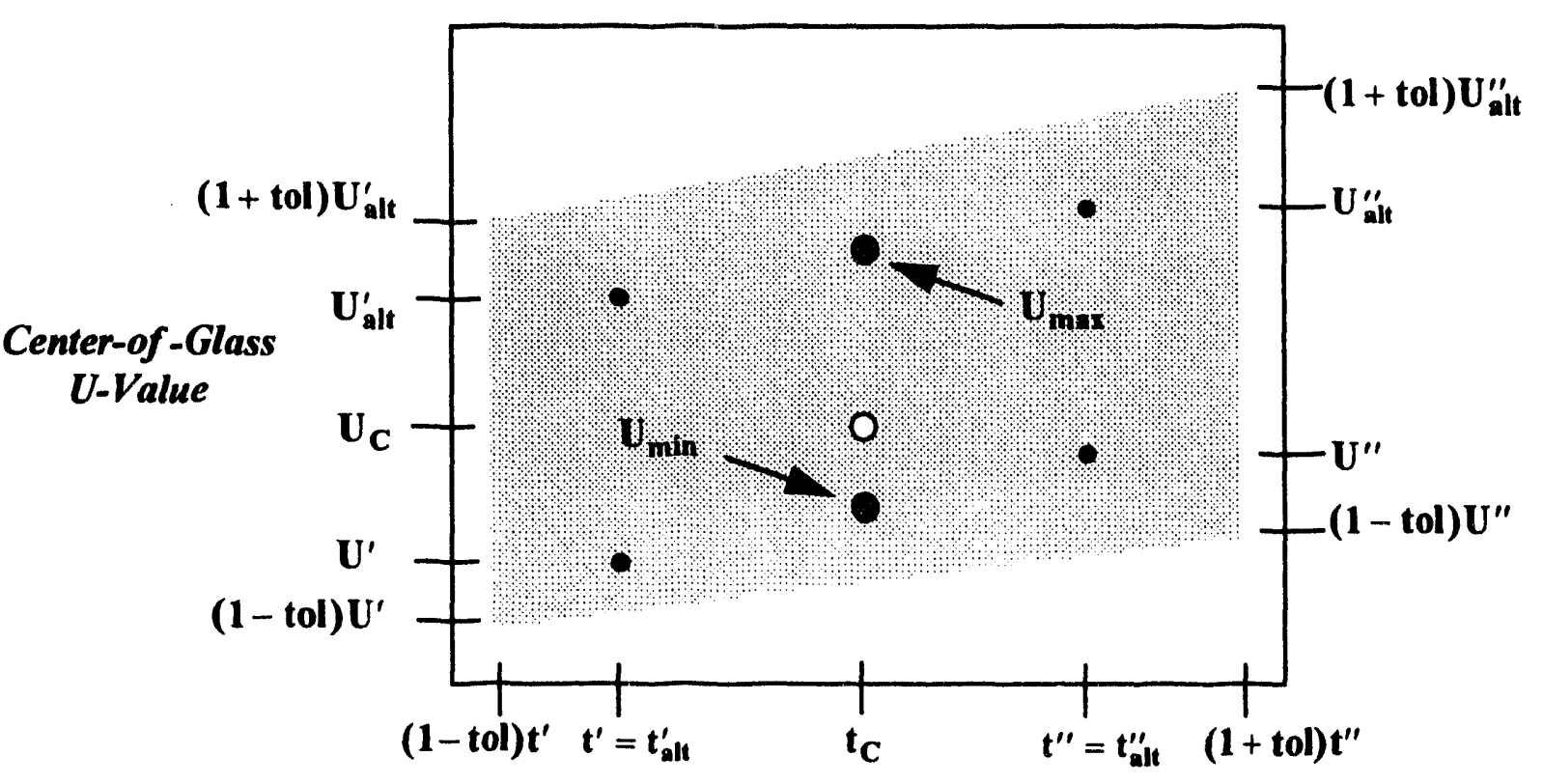

Glazing System Thickness

Figure 6.5 Tolerance criterion for a Type IV Simulation. The shaded area denotes the region of acceptable combinations of $U_{c}$ and $t_{c}$. The black dots indicate the properties of the glazing systems used in the FRAME simulation. The white dot indicates the properties of a glazing system that could be combined with this *.F30 file to create a total window. The gray dots are intermediate values that indicate the extreme values of the center-of-glass $U$ - value that are acceptable for a given $t_{c}$.

WINDOW calculates the frame and edge-of-glass U-values using a double interpolation. The program first determines maximum and minimum possible values of $U_{F}$ and $U_{E}$ using the thickness ratio, $R_{l}$, determined by Eq. 6.3.2i.

$$
\begin{aligned}
& U_{F_{\text {max }}}=U_{F_{\mathrm{alt}}}+R_{\mathrm{t}} \times\left(U_{\mathrm{F}_{\mathrm{alt}}}^{\prime}-U_{\mathrm{F}_{\text {alt }}}\right) \\
& \mathrm{U}_{\mathrm{F}_{\min }}=U_{\mathrm{F}}^{\prime}+R_{\mathrm{t}} \times\left(U_{\mathrm{F}}^{\prime \prime}-U_{\mathrm{F}}^{\prime}\right)
\end{aligned}
$$

n

$$
\begin{aligned}
& U_{E_{\max }}=U_{E_{a l t}}+R_{t} \times\left(U_{E_{a l t}^{\prime \prime}}-U_{E_{\text {alt }}}\right) \\
& U_{E_{\min }}=U_{E}^{\prime}+R_{t} \times\left(U_{E}^{\prime \prime}-U_{E}^{\prime}\right)
\end{aligned}
$$

The final values are based on the center-of-glass ratio as defined in Eq. 6.3.2h:

$$
\begin{aligned}
& U_{F}=U_{F_{\min }}+R_{U} \times\left(U_{F_{\min }}-U_{F_{\max }}\right) \\
& U_{E}=U_{E_{\min }}+R_{U} \times\left(U_{E_{\min }}-U_{E_{\max }}\right)
\end{aligned}
$$

Where $R_{U}$ is the center-of-glass ratio: $R_{U}=\frac{U_{C}-U_{\min }}{U_{\max }-U_{\min }}$ 


\subsection{LBL Dividers}

The DIVIDER LIBRARY contains default data for typical "divided-lite" or true dividers and "suspended" or between glass dividers, see Fig. 6.4. Correlations for divider U-value and divider edge U-value were obtained through the use of finite element modeling at Lawrence Berkeley Laboratory [Acevedo-Ruiz, 1991]. The correlations are functions of the center of glass $U$-value $\left(U_{C}\right)$ and the gap width $(\omega)$. For suspended dividers, the divider is assumed to have a thickness, $x_{s}$, of $4.8 \mathrm{~mm}$. Correlations for five dividers are provided in WINDOW 4.0. The correlations are best fit polynomials. The coefficients for these polynomials in SI units are found in Tables 6.2 and 6.3.

$$
\begin{aligned}
& U_{D E}=A+B x_{g}+C U_{g}+D U_{g}^{2} \\
& U_{D}=E+F x_{g}+G x_{g}^{2}+H U_{g}+I U_{g}^{2}
\end{aligned}
$$

\begin{tabular}{|l|l|l|l|l|l|l|}
\hline Divider Type & Gap width $(\mathrm{mm})$ & Corr \# & $\mathrm{A}$ & $\mathrm{B}$ & $\mathrm{C}$ & $\mathrm{D}$ \\
\hline DIVIDED LITES & $\mathrm{x}_{\mathrm{g}}=\omega$ & & & & & \\
\hline Aluminum, hollow & $6.35<\omega<19.05$ & 1 & 1.19 & 0.00 & 0.73 & 0.009 \\
\hline Butyl, solid/Al backing & $6.35<\omega<19.05$ & 2 & 1.02 & 0.00 & 0.74 & 0.014 \\
\hline Wood, solid & $6.35<\omega<19.05$ & 3 & 0.443 & 0.00 & 0.85 & 0.019 \\
\hline $\begin{array}{l}\text { Insulating material, solid } \\
(0.021 \text { W/m-K) }\end{array}$ & $6.35<\omega<19.05$ & 4 & 0.114 & 0.00 & 0.91 & 0.016 \\
\hline SuSPENDED DIVIERS & $\mathrm{x}_{\mathrm{g}}=\left(\omega-\mathrm{x}_{\mathrm{g}}\right) / 2.0$ & & & & & \\
\hline Aluminum, hollow & $0.00<\omega<0.724$ & 5 & 1.02 & -0.543 & 0.86 & 0.000 \\
\hline Aluminum, hollow & $0.724<\omega<7.09$ & 5 & -0.0273 & 0.00 & 1.08 & -0.0093 \\
\hline Vinyl, hollow & $0.00<\omega<7.09$ & 6 & 0.008 & 0.00 & 1.02 & -0.0008 \\
\hline
\end{tabular}

Table 6.2 Coefficients for calculating divider edge U-values

\begin{tabular}{|l|l|l|l|l|l|l|}
\hline Divider Type & Corr \# & E & F & G & H & I \\
\hline DIVIDED LITES & & & & & & \\
\hline Aluminum, hollow & 1 & 5.56 & 0.0004 & -0.00003 & 0.042 & -0.003 \\
\hline Butyl, solid/Al backing & 2 & 4.66 & -0.029 & 0.0008 & 0.13 & -0.005 \\
\hline Wood, solid & 3 & 4.26 & -0.241 & 0.0054 & 0.63 & -0.063 \\
\hline $\begin{array}{l}\text { Insulating material, solid } \\
(0.021 \text { W/m-K) }\end{array}$ & 4 & 1.82 & -0.1587 & 0.0042 & 0.69 & -0.023 \\
\hline SuSPENDED DIVIDERS & & & & & & \\
\hline Aluminum, hollow & 5 & 0.00 & -3.206 & 0.00 & 4.13 & -0.689 \\
\hline Aluminum, hollow & 5 & 1.25 & -0.583 & 0.048 & 1.50 & -0.171 \\
\hline Vinyl, hollow & 6 & 0.57 & -0.25 & 0.021 & 1.11 & -0.109 \\
\hline
\end{tabular}

Table 6.3 Coefficients for calculating divider U-values

\subsection{Generic Dividers}

Generic dividers are either modified LBL dividers or user supplied dividers. The user needs to enter a divider $U$-value and a divider edge $U$-value, the absorption of the divider and the projected divider dimension. LBL correlations can be used with generic dividers. 


\subsection{FRAME 3.0 Dividers}

The FRAME 3.0 program can be used to model divider and divider edge U-values. FRAME files are treated exastly the same way in the DIVIDER LIBRARY as in the FRAME LIBRARY, see Section 6.3.

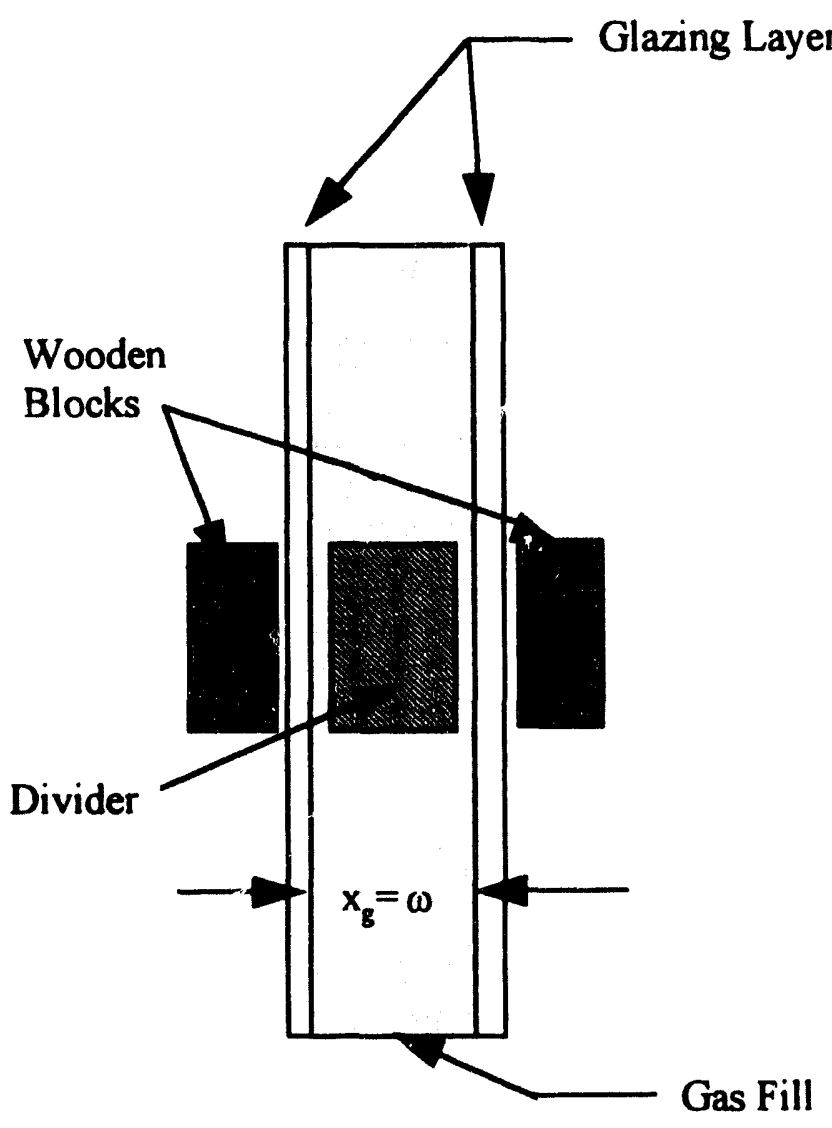

"Divided Lite"

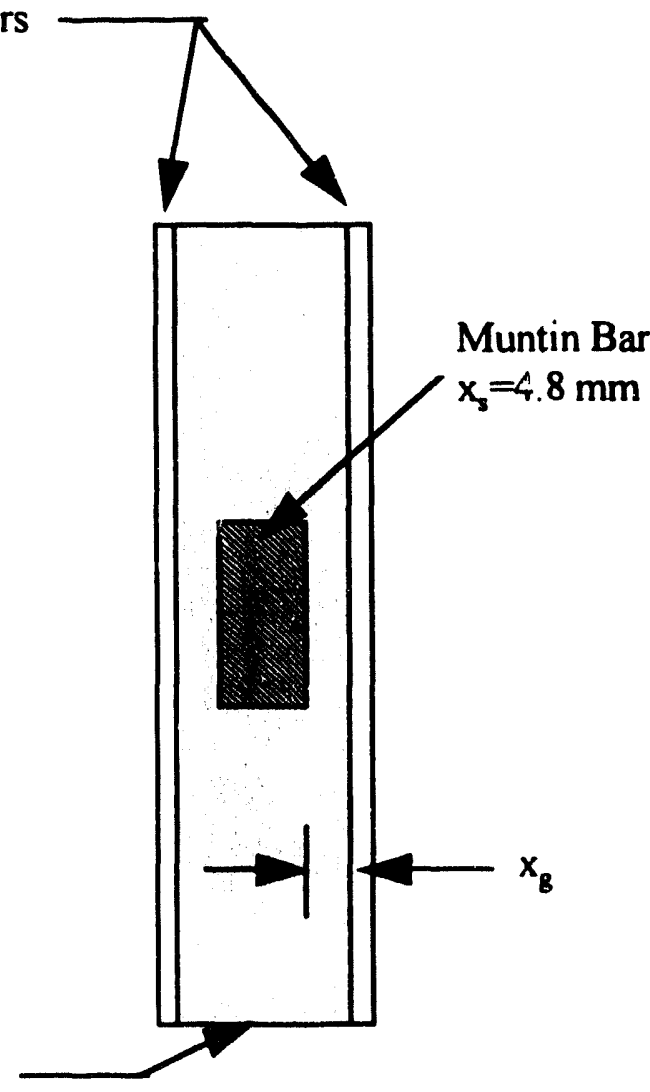

Suspended Divider

Figure 6.4 Examples of the "Divided Lite" and "Suspended Divider" default dividers found in WINDOW 4.0. These dividers should not be used in single layer glazing systems. For glazing systems with more than two glazir? layers, the dividers are assumed to be placed between the two outermost glazing layers.

\subsection{OPTICAL PROPERTIES}

The OPTICAL PROPERTIES SCREEN displays the results of many calculations. Discussion of the calculations associated with this screen covers overall normal, angular, and hemispherical properties for a multiple layer glazing system based on visible, solar, infrared and ultraviolet averaging. The calculation of the layer by layer solar absorptance is also discussed as is the angular variation of the Solar Heat Gain Coefficient. The above mentioned properties are calculated for all glazing systems. The OPTICAL PROPERTIES SCREEN also displays results from calculations that are only performed if spectral data is available for every glazing layer in the glazing system. These optical properties are the UV Transmittance, the Damage Weighted UV Transmittance, and the Color Calculations. The color results are based on calculations using both the transmittance and the front reflectance of the glazing system. These 
calculations include the determination of the Purity, the Dominant Wavelength and the CIE $L^{*}, a^{*}, b^{*}$ values.

\subsection{Determination of Overall Glazing System Properties}

Spectrally averaged optical properties for each layer of the glazing system is discussed in Sec 3.1. The OPTICAL PROPERTIES SCREEN displays the overall optical properties for the entire glazing system. The basic overall properties, transmittance, reflectance and absorptance, calculated for a glazing system are shown in Fig. 7.1
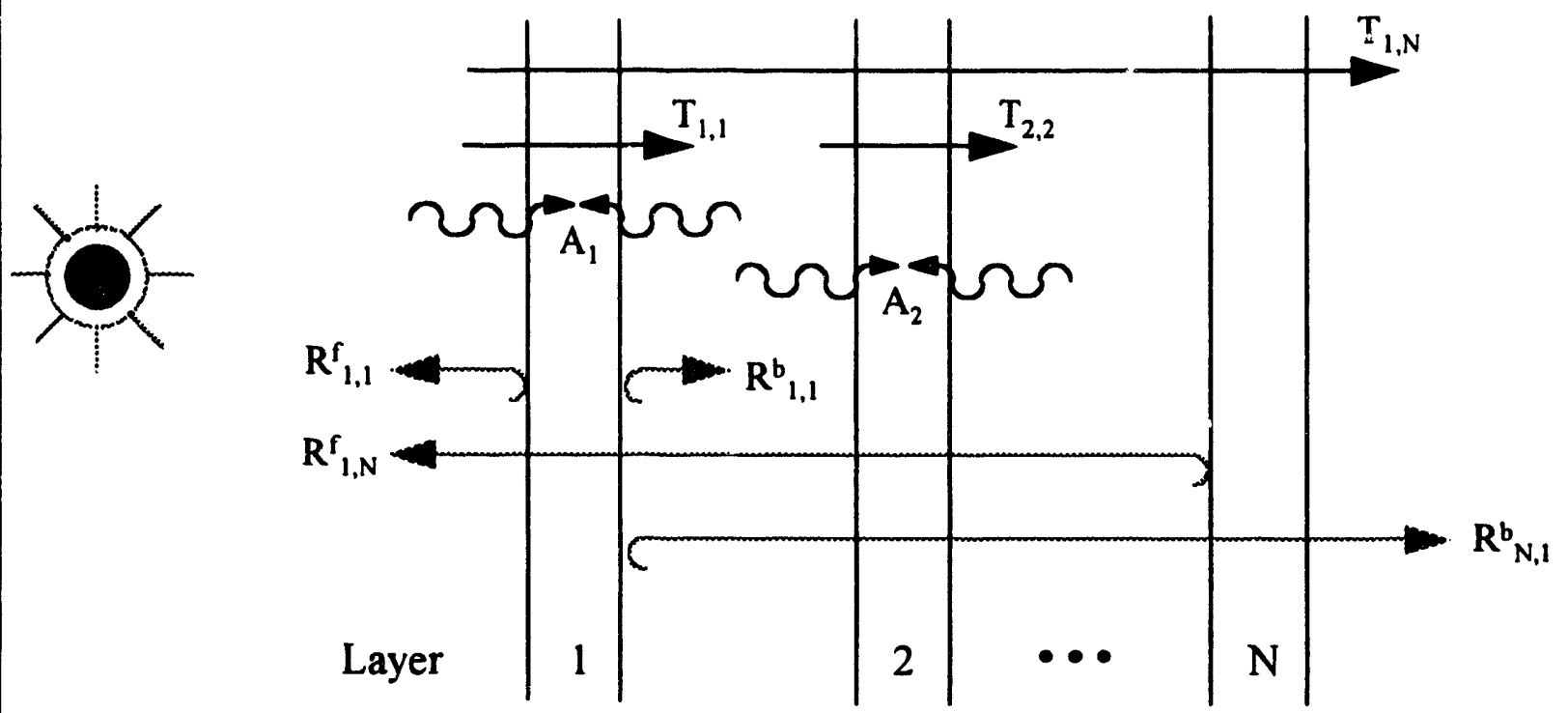

Figure 7.1 Schematic of transmission, reflection, and absorption of solar radiation within a multiple layer glazing system. Terms with single or equal subscripts are single layer properties: $T_{1,1}, \mathbf{R}_{1,1}^{f}, \mathbf{R}_{1,1}^{b}, A_{1}$. The overall properties are : $T_{1, N}, \mathbf{R}_{i, N}^{f}, \mathbf{R}_{N, 1}^{b}$.

WINDOW 4.0 calculates optical properties of total glazing systems in one of three ways depending on the availability of spectral data. A single band model is used if none of the glazing layers included in the glazing system have attached spectral data files. A multi-band model is used if all of the glazing layers included in the glazing system have attached spectral files. If some of the glazing layers have spectral data files and some do not then the program uses a combination of the multi-band and the single band models. In the combination model the program creates a pseudo-spectral data file for layers without spectral data files by assigning the average value of a property to every wavelength in the spectrum; a multi-band model on the entire assembly is then usud.

\subsubsection{Overall Transmittance and Reflectance}

The overall transmittance and reflectances of the glazing system are determined using iterative equations which take into account the multiple internal reflections within the glazing system. The equations are written with a spectral dependency but are equally valid for single band models. 


$$
\begin{aligned}
& T_{i, j}(\lambda)=\frac{T_{i, j-1}(\lambda) T_{j, j}(\lambda)}{1-R_{j, j}^{f}(\lambda) R_{j-1, i}^{b}(\lambda)} \\
& R_{i, j}^{f}(\lambda)=R_{i, j-1}^{f}(\lambda)+\frac{T_{i, j-1}^{2}(\lambda) R_{j, j}^{f}(\lambda)}{1-R_{j, j}^{f}(\lambda) R_{j-1, i}^{b}(\lambda)} \\
& R_{j, i}^{b}(\lambda)=R_{i, j-1}^{b}(\lambda)+\frac{T_{j, j}^{2}(\lambda) R_{j-1, i}^{b}(\lambda)}{1-R_{j, j}^{f}(\lambda) R_{j-1, i}^{b}(\lambda)}
\end{aligned}
$$

When the subscripts are equal the property referred to is the property of the single glazing layer. The iterative procedure is carried out until the transmittance and reflectances of the entire glazing system has been determined. This is equivalent to the case where $i=1$ and $j=N$, where $N$ is the number of glazing layers in the glazing system. Once the overall transmittance and reflectances have been calculated the angular dependence and hemispherical values of the properties can be determined, see Section 7.2 and 7.3. Finally the solar and visible averages can be performed as for a single glazing layer, see Section 3.1.

\subsubsection{Calculation of Absorption of Each Layer}

The absorption of each layer is calculated using iterative equations, Eqs. 7.1.2a-7.1.2c similar to those used to calculate the transmittance and the reflectances.

$A_{j}(\lambda)=\frac{T_{1, j-1}(\lambda) A_{j}^{f}(\lambda)}{1-R_{j, N}^{f}(\lambda) R_{j-1,1}^{b}(\lambda)}+\frac{T_{1, j}(\lambda) R_{j+1, N}^{f}(\lambda) A_{j}^{b}(\lambda)}{1-R_{j, 1}^{b}(\lambda) R_{j+1, N}^{f}(\lambda)}$

$A_{j}^{f}(\lambda)=1-T_{j, j}(\lambda)-R_{j, j}^{f}(\lambda)$

$A_{j}^{b}(\lambda)=1-T_{j, j}(\lambda)-R_{j, j}^{b}(\lambda)$

The subscript $j$ refers to the glazing layer. Layer $l$ is the outermost layer and layer $N$ is the inner most layer. The solar averaged value of the absorptance is determined using the methods outlined in Section 3.1. Once the value for the layer is calculated the angular dependence is determined using the methods presented in Section 7.2 and the hemispherical values are determined using the method presented in Section 7.3. The angular dependence of the Solar Heat Gain Coefficient is determined by using the angular values for the solar transmittance and absorbtance in Eq. 5.2a.

\subsection{Calculation of Angular Properties}

Many window applications require knowledge of the optical properties of glazings with incident radiation at off-normal incidence. Currently it is standard practice to measure optical properties at normal incidence. Most commercial spectroradiometers are constructed so that the light beam shines directly on the detector. This is a convenient configuration for transmittance measurements at normal incidence. Simply rotating the sample to obtain transmittance at off-normal incidence may offset the beam sufficiently to affect the measurement accuracy. In reflection, the beam will be directed away from the detector entirely. Furthermore, at oblique incidence, multiple reflections in the sample are separated into separate beams which must be properly collected. Accessories are available to measure both transmittance and reflectance at oblique angles, but they are not well integrated with the design of the base instrument. Instruments 
designed so that the detector and sample can move, in order to better measure angle-dependent optical properties, are call gonioradiometers. Existing gonioradiometers have deficiencies that make them unsuitable for routine measurements on glazing materials. Thus WINDOW includes a calculation scheme for determining the angular dependence of the glazing system optical properties. This calculation scheme is based on first principles for uncoated glass. For coated glass products the calculation procedure is less exact. The calculation of angular dependence of optical properties of ccated glass in one of the areas slated for future improvement.

\subsubsection{Angular Properties of Uncoated Glass}

WINDOW uses a method based on first principles for determining the angular dependence of the optical properties for uncoated glass. The algorithm used is described in a paper by Furler [1991]. A summary of the method is included here for completeness. The following discussion indicates a spectral dependence with a subscript $\lambda$. WINDOW uses the same method for uncoated glass whether or not spectral data is available. If there is no spectral data the angular dependence is calculated based on the single values for the transmittance and reflectance in the visible and solar range. In the visible range an average wavelength of $0.575 \mu \mathrm{m}$ is used in the calculations. In the solar range an average wavelength of $0.898 \mu \mathrm{m}$ is used.

The spectral data included in WINDOW contains the spectral transmittance,$T_{\lambda}$, and the spectral reflectance,$R_{\lambda}$. For uncoated glass the front and back surfaces have the same reflectance. These values are obtained from spectroradiometer measurements. The transmittance and the reflectance are related to the transmissivity and the reflectivity through the following relations:

$T_{\lambda}(\phi)=\frac{\tau_{\lambda}(\phi)^{2} e^{-\alpha_{\lambda} d / \cos \phi}}{1-\rho_{\lambda}(\phi)^{2} e^{-2 \alpha_{\lambda} d / \cos \phi}}$

and

$R_{\lambda}(\phi)=\rho_{\lambda}(\phi)\left(1+T_{\lambda}(\phi) e^{-\alpha_{\lambda} t / \cos \phi}\right)$

Where $d$ is the sample thickness, $\phi$ is the incident angle at which the property is being evaluated, and $\lambda$, is the wavelength at which the property is being evaluated. Also appearing in Eqs. 7.2.1a and 7.2.1 $\mathrm{b}$ are the spectral values of the reflectivity, $\rho_{\lambda}$, the transmissivity, $\tau_{\lambda}$, and the absorption coefficient, $\alpha_{\lambda}$; these properties are defined below.

The spectral reflectivity is calculated from Fresnels equations assuming unpolarized incident radiation:

$\rho_{\lambda}(\phi)=\frac{1}{2}\left(\left(\frac{n_{\lambda} \cos \phi-\cos \phi^{\prime}}{n_{\lambda} \cos \phi+\cos \phi^{\prime}}\right)^{2}+\left(\frac{n_{\lambda} \cos \phi^{\prime}-\cos \phi}{n_{\lambda} \cos \phi^{\prime}+\cos \phi}\right)^{2}\right)$

Where $n_{\lambda}$ is the ratio of the spectral index of refraction of the glass to the index of refraction of air. The index of refraction of air is unity. The angle of incidence measured in air is denoted by $\phi$ and the angle of incidence as it would be measured in the glass is denoted by $\phi^{\prime}$.

The spectral transmissivity is calculated from the reflectivity:

$\tau_{\lambda}(\phi)=1-\rho_{\lambda}(\phi)$ 
And the spectral absorption coefficient is defined as:

$\alpha_{\lambda}=4 \pi \kappa_{\lambda} / \lambda$

Where $\kappa_{\lambda}$ is the dimensionless spectrally dependent extinction coefficient and $\lambda$ is the wavelength expressed in the same units as the sample thickness to allow for a nondimensional exponential in Eqs. 7.2.1.a and 7.2.1b.

In order to determine the angular dependency of the transmittance and the reflectance the program first solves for the index of refraction and the extinction coefficient defined in Eqs. 7.2.1f and 7.2.1g. The spectral index of refraction can be found by inverting a special form of Eq. 7.2.1c evaluated at normal incidence.

$\mathrm{n}_{\lambda}=\frac{1+\sqrt{\rho_{\lambda}(0)}}{1-\sqrt{\rho_{\lambda}(0)}}$

Using Eq. 7.2.1b evaluated at normal incidence an expression for the spectral extinction coefficient is obtained.

$k_{\lambda}=-\frac{\lambda}{4 \pi t} \ln \left(\frac{R_{\lambda}(0)-\rho_{\lambda}(0)}{\rho_{\lambda}(0) T_{\lambda}(0)}\right)$

In order to solve Eqs. 7.2.If and 7.2.1g the value for the reflectivity at normal incidence must be known. This value is determined by combining Eqs. 7.2.1a and 7.2.1b to eliminate the exponential factor, resulting in the following expression:

$\rho_{\lambda}(0)=\frac{\beta-\sqrt{\beta^{2}-4\left(2-R_{\lambda}(0)\right) R_{\lambda}(0)}}{2\left(2-R_{\lambda}(0)\right)}$

where

$\beta=T_{\lambda}(0)^{2}-R_{\lambda}(0)^{2}+2 R_{\lambda}(0)+1$

All the values necessary for evaluating Eqs. 7.2.1 h and 7.2.1 $\mathrm{i}$ are given in the spectral data file. The value for the reflectivity is back substituted into Eqs. 7.2.1f and 7.2.1g. The result from Eq. 7.2.1g is used to calculate the absorption coefficient in Eq. 7.2.1e. The index of refraction is used to calculate the reflectivity in Eq. 7.2.1 $\mathrm{c}$ which is then used to calculate the transmissivity in Eq. 7.7.1d. The reflectivity, transmissivity and absorption coefficient are then back substituted into Eq. 7.2.1a and 7.2.1 b to obtain the angular values of the reflectance and the transmittance. The spectral data is measured on commercially available thicknesses of glass. For some wavelengths the measured transmittance is zero. These values will cause Eq. 7.2.1g to be undefined. There is a safeguard in WINDOW that sets the extinction coefficient to zero if the transmittance is zero. 


\subsubsection{Angular Properties for Coated Glass}

Starting with properties measured at normal incidence, WINDOW uses a regression fit to calculate the angular dependence of optical properties of coated glass. If the transmittance is greater than 0.645 the coated glass is modeled assuming the angular dependence of clear glass, if the transmittance is less than or equal to 0.645 the coated glass is modeled assuming the angular dependence of bronze glass. The values for the angular functions for the transmittance and reflectance of both clear glass $\left(\bar{\tau}_{\mathrm{clr}}, \bar{\rho}_{\mathrm{clr}},\right)$ and bronze glass $\left(\bar{\tau}_{\mathrm{bnz}}, \bar{\rho}_{\mathrm{bnz}}\right)$ are determined from a fourth order polynomial regression.

$\bar{\tau}(\phi)=\bar{\tau}_{0}+\bar{\tau}_{1} \cos (\phi)+\bar{\tau}_{2} \cos ^{2}(\phi)+\bar{\tau}_{3} \cos ^{3}(\phi)+\bar{\tau}_{4} \cos ^{4}(\phi)$

and

$\bar{\rho}(\phi)=\bar{\rho}_{0}+\bar{\rho}_{1} \cos (\phi)+\bar{\rho}_{2} \cos ^{2}(\phi)+\bar{\rho}_{3} \cos ^{3}(\phi)+\bar{\rho}_{4} \cos ^{4}(\phi)-\bar{\tau}(\phi)$

Where $\phi$ is the angle of incidence with normal incidence defined as $\phi=0.0$. The coefficients for the polynomial can be found in Table 7.1.

\begin{tabular}{|l|l|l|l|l|l|}
\hline & $\mathbf{0}$ & $\mathbf{1}$ & $\mathbf{2}$ & $\mathbf{3}$ & $\mathbf{4}$ \\
\hline$\overline{\boldsymbol{\tau}}_{\mathbf{c l r}}$ & -0.0015 & 3.355 & -3.840 & 1.460 & 0.0288 \\
\hline$\overline{\mathbf{P}}_{\text {clr }}$ & 0.999 & -0.563 & 2.043 & -2.532 & 1.054 \\
\hline$\overline{\boldsymbol{\tau}}_{\text {bnz }}$ & -0.002 & 2.813 & -2.341 & -0.05725 & 0.599 \\
\hline$\overline{\mathbf{P}}_{\text {bnz }}$ & 0.997 & -1.868 & 6.513 & -7.862 & 3.225 \\
\hline
\end{tabular}

Table 7.1. Coefficients for Clear and Bronze angular dependence regression formulas used for calculating the angular properties of coated glass.

Once these factors are calculated they are applied to the normal transmittance and reflectances of the glass. This is done at each wavelength if spectral data is available or for a single value if no spectral data is attached.

The angular transmittances and reflectances are calculated using the following formulas:

For $\tau_{\lambda}>0.645$ :

$\tau_{\lambda}(\phi)=\tau_{\lambda} \times \bar{\tau}_{\mathrm{clr}}(\phi)$

$\rho_{\lambda}(\phi)=\rho_{\lambda} \times\left(1-\bar{\rho}_{\mathrm{clr}}(\phi)\right)+\bar{\rho}_{\mathrm{clr}}(\phi)$

for $\tau_{\lambda} \leq 0.645$

$\tau_{\lambda}(\phi)=\tau_{\lambda} \times \bar{\tau}_{\text {bnz }}(\phi) \quad: \tau_{\lambda} \leq 0.645$

$\rho_{\lambda}(\phi)=\rho_{\lambda} \times\left(1-\bar{\rho}_{b n z}(\phi)\right)+\bar{\rho}_{b n z}(\phi)$ 


\subsection{Calculation of Hemispherical Values}

Once the angular values of the properties are known the hemispherical values are determined by a numerical integration (see Section 3.1.1) using the following integral:

$$
P_{\cap}=2 \int_{0^{\circ}}^{90^{\circ}} P(\phi) \cos (\phi) \sin (\phi) d \phi
$$

\subsection{Ultraviolet Transmittance}

If each glazing layer in the glazing system has a spectral data file with a minimum value less than or equal to $\mathbf{0 . 3 0}$ microns then the Ultraviolet Transmittance averages are calculated. The UV Transmittance values are calculated using the same procedure as for the other optical properties, see Section 3.1. The necessary values for Eq. 3.1 are given in Table 7.2.

\begin{tabular}{|l|l|l|l|l|l|}
\hline $\begin{array}{l}\text { "x" Property "P" Property } \\
\text { Classification }\end{array}$ & $\begin{array}{l}\text { "a" Lower "b" Upper } \\
\text { Wavelength } \\
(\mu \mathrm{m})\end{array}$ & $\begin{array}{l}\text { "Eavelength Spectral " } \\
\text { Wam } \\
(\mu \mathrm{m})\end{array}$ & $\begin{array}{l}\text { Weighting Auxiliary } \\
\text { Function }\end{array}$ & Function \\
\hline UV & Transmittance & 0.30 & 0.39 & Solspect.dat $^{\prime}$ & $1.0^{2}$ \\
\hline $\begin{array}{l}\text { DW - Damage } \\
\text { Weighted UV }\end{array}$ & Transmittance & 0.30 & 0.50 & Solspect.dat & $\begin{array}{l}\text { Krochmann Damage } \\
\text { Function }\end{array}$ \\
\hline
\end{tabular}

Table 7.2 Values necessary to solve Eq. 3.1.1a for the UV Transmittance

\section{Notes for Table 7.2:}

1. Solar weighting function found in ASTM E-891 1987, Table 1.

2. This assumes that all radiation in the range of $0.30-0.39 \mu \mathrm{m}$ is treated equally and that everything outside of this range is not relevant to the "UV."

3. The Krochmann Damage Function is an exponential function (Lichttechnik, 1978): $\Gamma_{\text {DUV }}=\exp (12.28-22.56 \lambda) / 100$ where $\lambda$ is measured in microns. It has a value of 1.0 at $0.30 \mu \mathrm{m}$ and decreases exponentially to approximately 0.0 at $0.50 \mu \mathrm{m}$. The use of this function allows all wavelengths which cause damage to be included while still giving weight to those which are more prone to cause damage.

\subsection{Calculation of the Color Properties}

WINDOW 4.0 calculates the Dominant Wavelength, Purity and CIE $L^{*}, a^{*}, b^{*}$ values for glazing systems if each glazing layer has an attached spectral data file. The color calculations are based on the recommendations presented in ASTM E308 - 90. A more complete discussion of color properties can be found in ASTM E308 or in the IES Lighting Handbook [Kaufman, 1984]. The calculation requires spectral data files and three additional files: CIE64T.DAT, CIE64C.DAT and ILLD65.DAT. CIE64T.DAT contains the spectral tristimulus values (Color Matching Functions $\bar{x}_{10}, \bar{y}_{10}, \bar{z}_{10}$ ) for the CIE 1964 Supplementary Standard $\left(10^{\circ}\right)$ Observer. CIE64C.DAT contains the coordinates of the spectrum locus. ILLD65.DAT contains the spectral weighting function recommended for use when calculating color recognition for objects exposed to daylight, Illuminant D65. 
The color properties are functions of the chromaticity coordinates of the glazing system. These coordinates are determined from the spectral values for transmittance and front reflectance for the glazing system, calculated using Eqs. 7.1.1a and 7.1.1b; and from the spectral distribution of the light source. The color values based on transmittance are of interest for color perception of an observer located inside a building. The color values based on reflectance are of interest for color perception of an observer located outside the building.

\subsubsection{Calculation of the Chromaticity Coordinates}

The chromaticity coordinates $\mathrm{x}, \mathrm{y}$, and $\mathrm{z}$ are calculated using the following method.

1). Calculate the total tristimulus values $X, Y$, and $Z$.

$$
\begin{aligned}
& X=\int_{.38}^{.78} P(\lambda) S(\lambda) \bar{x}_{10}(\lambda) d \lambda / \int_{.38}^{.78} S(\lambda) \bar{y}_{10}(\lambda) d \lambda \\
& Y=\int_{.38}^{.78} P(\lambda) S(\lambda) \bar{y}_{10}(\lambda) d \lambda / \int_{.38}^{.78} S(\lambda) \bar{y}_{10}(\lambda) d \lambda \\
& Z=\int_{.38}^{.78} P(\lambda) S(\lambda) \bar{z}_{10}(\lambda) d \lambda / \int_{.38}^{.78} S(\lambda) \bar{y}_{10}(\lambda) d \lambda
\end{aligned}
$$

Where $P(\lambda)$ is the spectral value of the property under consideration either transmittance or reflectance and $S(\lambda)$ is the value of the spectral distribution of the illuminant. The spectral weighting functions of the illuminant are given every $0.05 \mu \mathrm{m}$. If the spectral data for the glazing system is at different wavelengths, a linear interpolation is performed to estimate the value of the properties at the required wavelengths.

In WINDOW 4.0 the exact integration has been replaced with a numerical integration based on the trapezoid rule, see Section 3.1.1. This provides a more accurate approximation to an exact integral than does the simple summation suggested in ASTM E308.

2). The chromaticity coordinates are obtained by normalizing the tristimulus values:

$$
\begin{aligned}
& x=X /(X+Y+Z) \\
& y=Y /(X+Y+Z)
\end{aligned}
$$

Once the chromaticity coordinates of the sample are known the color property values reported in WINDOW 4.0 can be calculated.

\subsubsection{Calculation of the Dominant Wavelength and Purity}

The Dominant Wavelength and the Excitation Purity relate to the color appearance of the glazing system. These values are indications of where the chromaticity coordinates of the sample lie with respect to the chromaticity coordinates of the light source and to the spectrum locus. The Dominant Wavelength is defined as the point where a line passing through the chromaticity coordinates of the light source and the sample intersect the spectrum locus. 
In order to determine the Dominant Wavelength of the sample, the chromaticity coordinates of the source $\left(x_{n}, y_{n}\right)$ are needed. These values are calculated using Eqs. 7.5.1a-e with $P(\lambda)$ set equal to 1.0 for each wavelength. Once the chromaticity coordinates of the source and the glazing system are known, the dominant wavelength is calculated using the following method.

1). The angle of the line connecting the source and the glazing system is determined by taking the inverse tangent of the slope:

$\psi=\tan ^{-1}\left(\frac{y_{n}-y}{x_{n}-x}\right)$

2). The angle between the coordinates of the spectrum locus and the chromaticity coordinates for the source is then calculated. If the angle between the sample and the source is greater than the angle associated with $0.38 \mu \mathrm{m}$ and less than the angle associated with $0.78 \mu \mathrm{m}$, the line intersects the purple line. In this case the complimentary wavelength is reported. For example a red sample would have a reported dominant wavelength of $0.5 \mu \mathrm{m}$ which is in the green range.

3). WINDOW does a simple search until the angle between sample and source is bracketed by adjacent angles between the source and the pure color chromaticity curve. WINDOW calculates the point of intersection between the line connecting the source, sample and chromaticity curve and a straight line connecting the adjacent points of the curve. The dominant wavelength is determined using linear interpolation based on the distance between the point of intersection and the endpoints that intersect the chromaticity diagram at the bracketing points.

4). The Excitation Purity is the ratio of the distance between the source and the sample and the distance between the source and the point of intersection with the chromaticity curve.

\subsubsection{Calculation of the CIE $L^{*}, a^{*}, b^{*}$ Values}

Window also calculates the CIE $L^{*}, a^{*}, b^{*}$ values. These values represent where the sample lies in the CIE uniform color space. The uniform color space is formed by the mutually perpendicular $L^{*} a^{*}$ and $b^{*}$ axes. The $a^{*}$ axis has values from -150 which is pure green to 150 which is pure red. The $b^{*}$ axis has values from -150 which is pure blue to 150 which is pure yellow. The $L^{*}$ axis also passes through the zero intersection point and has values of zero which is black to 100 which is white. The $L^{*}, a^{*}, b^{*}$ coordinates are functions of the ratios $X / X_{n}, Y / Y_{n}$, and $Z / Z_{n}$.

$$
\begin{aligned}
& L^{*}=116\left(Y / Y_{n}\right)^{1 / 3}-16: Y / Y_{n}>0.008856 \\
& L^{*}=903.3\left(Y / Y_{n}\right): Y / Y_{n} \leq 0.008856 \\
& a^{*}=500\left[f\left(X / X_{n}\right)-f\left(Y / Y_{n}\right)\right] \\
& b^{*}=200\left[f\left(Y / Y_{n}\right)-f\left(Z / Z_{n}\right)\right]
\end{aligned}
$$

where:

$$
f(R)=(R)^{1 / 3} \quad R>0.008856 \quad: R=X / X_{n}, Y / Y_{n}, \text { or } Z / Z_{n} .
$$

and $f(R)=7.787(R)+16 / 116 \quad R \leq 0.00856$ 


\subsection{TEMPERATURE SCREEN}

The TEMPERATURE SCREEN displays two center-of-glass temperature profiles and the relative humidity at which condensation forms. A profile is shown for the U-value and Solar parts of the environmental conditions. The relative humidity is based on the U-value conditions.

\subsection{Temperature Profile}

In order to determine the temperature profile the glazing system is divided into a network of nodes. Each solid layer in the glazing system has three nodes, one at the center and one at each surface, see Fig. 8.1.

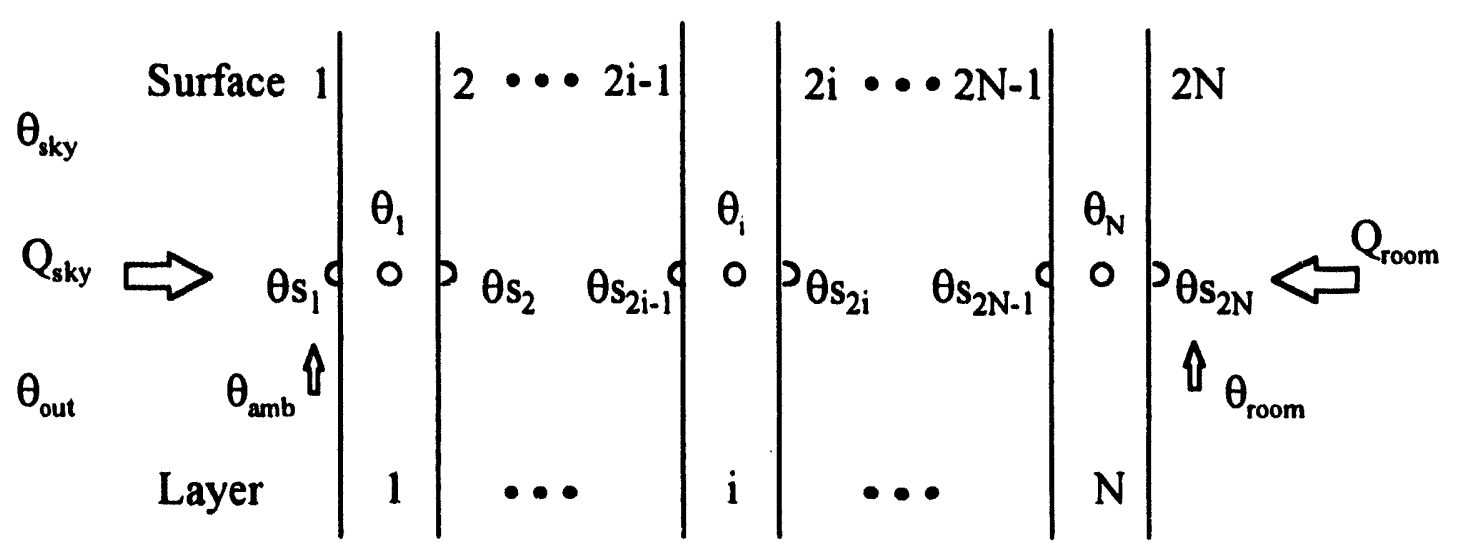

Figure 8.1 A schematic of the location of nodes and the definition of temperatures and external heat fluxes used to determine the temperature profile across the glazing system.

The glazing is exposed to radiant heat flux from the outside, $Q_{\text {sky }}$, and from the inside, $Q_{\text {room }}$. The glazing is also exposed to forced convection on the external surface and natural convection on the interior surface. It is assumed that the environmental conditions are constant and that the window is at steady state. The steady state assumption requires that at any node the net heat flux is zero:

$\mathbf{Q}_{i}=\left(\theta_{i}-\theta_{i-1}\right) / \mathbf{R}_{\mathbf{i}}+\left(\theta_{i}-\theta_{i+1}\right) / \mathbf{R}_{i+1}-\mathbf{Q}_{a_{b s}}=0$

$\theta_{i}$ is the temperature evaluated at the midpoint of the layer $i . R_{i}$ is the thermal resistance between adjacent midpoints and includes the effects of conduction, convection and radiation heat transfer. $Q_{a b s i}$ is the fraction of the incident radiation absorbed by the layer: $Q_{a b s}=A_{i}^{\text {sol }} Q_{s k y}$. The calculation of the solar absorptance of each layer of the glazing system, $A_{i}^{\text {sol }}$, is discussed in Section 7.1.2.

\subsection{Outline of the Temperature Profile Algorithm}

Equation 8.1 provides a means for determining the temperature distribution across the glazing system. Initially, a linear temperature profile across the glazing system is assumed. This initial profile is systematically modified until it satisfies Eq. 8.1. For the final temperature profile all values of $Q_{i}$, the net heat flux for each node, are approximately zero (less than 0.01 ). Determination of the temperature profile is a nonlinear problem since the thermal resistance, $\mathbf{R}_{i}$, is a function of temperature. The thermal resistances must be recalculated for each new temperature profile until convergence is reached. Figure 8.2 gives a flow chart of the process. This section elaborates on this flow chart. 


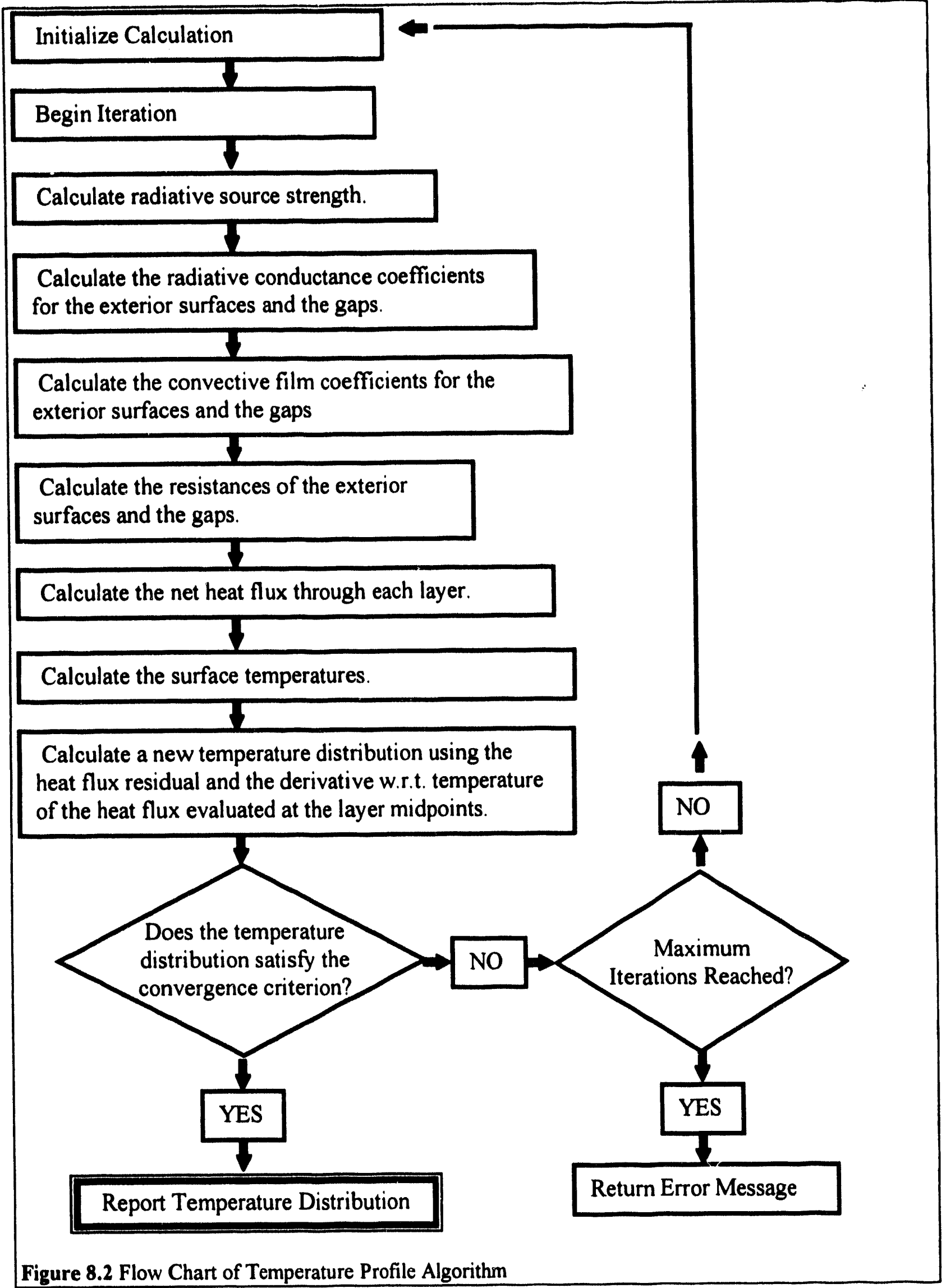


8.2.1 Initialize Calculation This step sets up the initial temperature distribution across the glazing system. This initial profile assumes that the temperature across each layer is constant and that the temperature varies linearly layer by layer. In addition, the infrared radiative transfer matrix is set up. This $2 \mathrm{~N} \times 2 \mathrm{~N}$ matrix, $M_{i, j}$, is a derived from an energy balance of the infrared radiation evaluated for each glazing surface of the window. In index notation this matrix equation is written:

$M_{i, j} Q_{i}^{r}=S_{j}$

Where:

$$
\begin{array}{ll}
M_{i, i}=1 \quad \quad \text { and } & S_{1}=\sigma \varepsilon_{1} \theta s_{1}^{4}+R_{1,1}^{f} Q_{s k y}^{r} \\
M_{2 i-1,2 i-2}=-R_{i, i}^{f} & S_{2}=\sigma \varepsilon_{1} \theta s_{2}^{4}+T_{1,1} Q_{s k y}^{r} \\
M_{2 i-1,2 i+1}=M_{2 i, 2 i-2}=-T_{i, i} & S_{2 i-1}=\sigma \varepsilon_{2 i-1} \theta s_{2 i-1}^{4} \\
M_{2 i, 2 i+1}=-R_{i, i}^{b} & S_{2 i}=\sigma \varepsilon_{2 i} \theta s_{2 i}^{4} \\
& S_{2 N-1}=\sigma \varepsilon_{2 N-1} \theta s_{2 N-1}^{4}+T_{N, N} Q_{r o o m}^{r} \\
& S_{2 N}=\sigma \varepsilon_{2 N} \theta s_{2 N}^{4}+R_{N, N}^{b} Q_{\text {room }}^{r}
\end{array}
$$

The values for the incident radiative flux are determined from the environmental conditions specified from within WINDOW 4.0:

$$
\begin{aligned}
& Q_{s k y}^{r}=\sigma \varepsilon_{s k y} \theta_{s k y}^{4} \\
& Q_{r o o m}^{r}=\sigma \theta_{\text {room }}^{4}
\end{aligned}
$$

Window inverts the infrared transfer matrix, $M_{i, j}$, to allow for the subsequent solution for $Q_{i}^{r}$ :

$$
Q_{i}^{r}=\left(M_{i, j}\right)^{-1} S_{j}
$$

8.2.2 Begin Iteration This step is a place marker. It is the point in the calculation where the program returns until the convergence criterion is satisfied or an error message is returned.

8.2.3 Calculation of radiative source strength Using the current temperature distribution determine the values of the radiative source vector $S_{j}$ as defined in Eq. 8.2.1a.

8.2.4 Calculation of the radiative conductance coefficients for exterior surfaces and gaps This is done by first solving Eq. 8.2e for the values of $Q_{i}^{r}$. The radiative conductance coefficients are then determined by dividing the radiative heat flux by the surface temperature difference:

$$
\begin{aligned}
& h_{\text {out }}=\left(Q_{\text {sky }}^{r}-Q_{1}^{r}\right) /\left(\theta_{\text {sky }}-\theta_{s_{1}}\right) \\
& h_{\text {in }}=\left(Q_{2 N}^{r}-Q_{\text {room }}^{r}\right) /\left(\theta_{s_{2 N}}-\theta_{\text {room }}\right) \\
& {h r_{\text {gap }}}^{r}=\left(Q_{2 i}^{r}-Q_{2 i+1}^{r}\right) /\left(\theta_{s_{2 i}}-\theta_{s_{2 i+1}}\right)
\end{aligned}
$$


8.2.5. Calculation of convective film coefficients for the external surfaces and the gaps The convective film coefficients $h c_{\text {out }}, h c_{i n}$, and $h c_{\text {gap }}$ are determined using the following methodologies. The heat transfer coefficients in WINDOW 4.0 are determined using the methodology found in Arasteh [1989]. The discussion is included here for completeness. WINDOW 4.0 uses empirical correlations to determine the heat transfer coefficients governing convection in the window. Correlations are used to calculate the heat transfer coefficients on the interior surface of the window, on the exterior surface of the window and in the gaps of the glazing system.

\section{Interior Film Coefficient}

The interior surface film coefficient is a function of both the temperature difference between the interior surface and the room temperature and the angular orientation of the window. The convective heat transfer coefficient in W/m $\mathrm{m}^{2}$. C for natural convection between room air and a vertical plate is based on experimental data and is given by ASHRAE [1989]:

$$
h=1.77\left(\left|\theta s_{2 N}-\theta_{\text {room }}\right|\right)^{0.25}
$$

The effect of the tilt on the value of $h$ is introduced through data provided by Konrad and Larsen (1978). Values are given for the tilt, $\phi$, at $90^{\circ}, 45^{\circ}, 0^{\circ}$. Two sets of numbers are given for tilts of $45^{\circ}$, and $0^{\circ}$, the value used depends on whether the surface is heated from below (warm inside cool outside) or above (cool inside warm outside). The values are found in the following table.

\begin{tabular}{|l|l|l|}
\hline$\phi^{\circ}$ & $\begin{array}{l}\mathrm{h}\left[\mathrm{W} / \mathrm{m}^{2} \mathrm{~K}\right] \\
\text { (heated from above) }\end{array}$ & $\begin{array}{l}\mathrm{h}\left[\mathrm{W} / \mathrm{m}^{2} \mathrm{~K}\right] \\
\text { (heated from below) }\end{array}$ \\
\hline 90 & 3.0415502 & \\
\hline 45 & 2.2477496 & 3.8353502 \\
\hline 0 & 0.9436496 & 4.0054502 \\
\hline
\end{tabular}

The values for intermediate angles are determined using linear interpolation. The interpolated value is normalized by the value at $90^{\circ}$. The final value of the interior heat transfer coefficient is obtained by multiplying the normalized value by the value obtained in $\mathrm{Eq}$ 8.2.5a.

\section{Exterior Film Coefficient}

The exterior film coefficient is a function of wind speed and direction relative to the window. Tilt is assumed to have negligible effect on the film coefficient [Shakerin, 1987].

On the windward side of the building $(|\Phi<\pi / 2|)$

$$
\begin{array}{ll}
\text { for } v>2 & h_{\text {out }}=8.07 v^{0.605} \\
\text { for } v<2 & h_{\text {out }}=12.27
\end{array}
$$

On the leeward side of the building $(|\Phi \geq \pi / 2|)$

$$
h_{\text {out }}=18.64(0.3+0.05 v)^{0.605}
$$

Note that at a wind speed of $0 \mathrm{~m} / \mathrm{s}$, the exterior film coefficient defined by this correlation is much higher than the interior film coefficient. This raises doubts about this correlation's accuracy at low wind speeds. 
Current research is aimed at developing a new correlation for the exterior film coefficient as a function of wind speed that is accurate at both high and low wind speeds.

\section{Gap Film Coefficient}

The heat transfer coefficient through the gaps accounts for conduction and convection and is referred to as a conductance. The conductance is defined as

$h=k \cdot N u / \omega$

Where $k$ is the thermal conductivity of the gas in the gap, $\omega$ is the width of the gas gap, and Nu is the gap Nusselt number. Elsherbiny [1982] presents an experimentally determined correlation for the Nusselt number for vertical windows and specific conditions:

$\mathrm{Nu}=\left[1+\left(0.0303 \mathrm{Ra}^{0.402}\right)^{11}\right]^{0.091} \quad$ for $\mathrm{Ra}<2 \times 10^{5}$

where $\mathrm{Ra}$, the Rayleigh number, is the product of the Grashoff (Gr) and Prandtl (Pr) numbers. The above correlation is given for an aspect ratio (height/total gap width) of 40 , typical for common windows. These expressions do not change significantly for larger, or slightly smaller aspect ratios.

The Grashoff number is defined as:

$\mathrm{Gr}=\frac{\mathrm{g} \beta \rho^{2} \omega^{3} \Delta \theta}{\mu^{2}}$

where $g$ is the gravitational acceleration $\left(9.8 \mathrm{~m} / \mathrm{s}^{2}\right), \beta$ is the coefficient of thermal expansion and is approximated by the inverse of the absolute mean temperature across the gap, $\rho$ is the density, $\Delta \theta$ is the temperature difference across the gap and $\mu$ is the viscosity. The calculation of properties for gas mixtures is found in Section 4.1. WINDOW 4.0 calculates the properties of the gas fill based on the average temperature of the gaps. In order to do this a value of the property at $273 \mathrm{~K}$ is given along with the derivative of the property with respect to temperature. This derivative is assumed to be constant. First the average value across the gap is calculated based on the surface temperatures to the left and the right of the gap:

$\theta_{\mathrm{avg}}=.5 \times\left(\theta_{\text {left }}+\theta_{\text {right }}\right)$

Then the property is evaluated at the average temperature. The local value of a property, $\mathrm{P}$, is determined as:

$P(\theta)=P_{273}+\frac{d P}{d \theta} \times \theta_{\text {avg }}$

Correlations for $\mathrm{Nu}$ for tilted windows heated from below are taken from Hollands [1976] for windows inclined between $0^{\circ}$ and $60^{\circ}$, and from Elsherbiny [1982] for windows inclined between $60^{\circ}$ and $90^{\circ}$. Hollands [1976] found that $\mathrm{Nu}$ could be approximated by: 
$\mathrm{Nu}=1+1.44\left[1-\frac{1708}{\mathrm{Ra} \cos \phi}\right]^{*}\left(1-\frac{(\sin 1.8 \phi)^{1.6} 1708}{\mathrm{Ra} \cos \phi}\right)+\left[\left(\frac{\mathrm{Ra} \cos \phi}{5830}\right)^{1 / 3}-1\right]^{*}$

Where for any expression $\mathrm{X},[\mathrm{X}]^{*}$ is defined as

$[\mathbf{X}]=(|\mathbf{X}|+\mathbf{X}) / 2$

Elsherbiny [1982] conducted work for air layers inclined at $60^{\circ}$ and at $90^{\circ}$ over a wide range of aspect ratios. In WINDOW 4.0 the aspect ratio is set to 40 . For a $60^{\circ}$ inclination angle, $\mathrm{Nu}$ is the maximum of two possible Nusselt numbers:

$$
\begin{aligned}
& \mathrm{Nu}_{1}=\left[1+0.0936 \mathrm{Ra}^{0.318} /(1+\mathrm{G})^{7}\right]^{1 / 7} \\
& \mathrm{G}=0.5 /\left[1+(\mathrm{Ra} / 3160)^{20.6}\right]^{0.1} \\
& \mathrm{Nu}_{2}=(0.014+0.175 / \mathrm{A}) \mathrm{Ra}^{0.283} \\
& \mathrm{Nu}_{60}=\left[\mathrm{Nu}_{1}, \mathrm{Nu}_{2}\right]_{\max }
\end{aligned}
$$

For layers tilted between $60^{\circ}$ and $90^{\circ}$, linear interpolation is used between the relations for $60^{\circ}$ and $90^{\circ}$ [Elsherbiny 1982]. The application of these equations is extended to all gas fills heated from below.

For gas layers heated from above (i.e., a warmer exterior), the following relation is assumed [Fergusen 1984]:

$\mathrm{Nu}=1+\left(\mathrm{Nu}_{90}-1\right) \sin \phi$

where $\mathrm{Nu}_{90}$ represents the Nusselt number for a vertical layer given by Eq. 8.2.5h.

8.2.6 Calculation of the resistances of external surfaces and gaps There are three types of resistances within the glazing system: the resistance of the surface exposed to the exterior conditions, the resistance of the surface exposed to interior conditions, and the resistance of the surfaces exposed to the gap conditions.

For surface 1 of layer 1 which is exposed to the exterior environmental conditions:

$$
\begin{aligned}
& \mathbf{R h}_{\mathbf{l}}=\mathbf{l} /\left(\mathbf{h c _ { \text { out } }}+\mathbf{h r}_{\text {out }}\right) \\
& \mathbf{R k}_{\mathbf{l}}=.5 \mathbf{w}_{\mathbf{l}} / \mathbf{k}_{\mathbf{1}} \\
& \mathbf{R}_{\mathbf{l}}=\mathbf{R h}_{\text {out }}+\mathbf{R} \mathbf{k}_{\text {out }}
\end{aligned}
$$

For surface $2 \mathrm{~N}$ of layer $\mathrm{N}$ which is exposed to the interior environmental conditions:

$$
\begin{aligned}
& R h_{N}=l /\left(h c_{\text {in }}+h r_{\text {in }}\right) \\
& \mathbf{R} \mathbf{k}_{\mathbf{N}}=.5 \mathbf{w}_{\text {in }} / \mathbf{k}_{\text {in }} \\
& \mathbf{R}_{\mathbf{N}}=\mathbf{R}_{\mathbf{h}_{\text {in }}}+\mathbf{R}_{\mathbf{k}_{\text {in }}}
\end{aligned}
$$


For surfaces exposed to the gap conditions:

$$
\begin{aligned}
& \mathbf{R h}_{\mathbf{i}}=1 /\left(\mathbf{h c}_{\mathbf{g a p}_{\mathbf{i}}}+\mathbf{h r}_{\mathrm{gap}_{\mathbf{i}}}\right) \\
& \mathbf{R k}_{\mathbf{i}}=.5\left(\mathbf{w}_{\mathbf{i}} / \mathbf{k}_{\mathbf{i}}+\mathbf{w}_{\mathbf{i}+1} / \mathbf{k}_{\mathbf{i}+1}\right) \\
& \mathbf{R}_{\mathbf{i}}=\mathbf{R h}_{\mathbf{g a p}_{\mathbf{i}}}+\mathbf{R k}_{\mathbf{g a p}_{\mathbf{i}}}
\end{aligned}
$$

8.2.7 Calculation of the heat transfer through each layer using the form of Eq. 8.1

$$
\Delta_{i}=\left(\theta_{i}-\theta_{i-1}\right) / \mathbf{R}_{i}+\left(\theta_{i}-\theta_{i+1}\right) / R_{i+1}-Q_{a b s}
$$

The intermediate net heat transfer through the midpoint of each layer is called the residual, $\Delta_{\mathrm{i}} . \theta_{0}$ equals $\theta_{\mathrm{amb}}$, see Section 8.4, and $\theta_{\mathrm{N}}$ equais $\theta_{\text {room }}$.

\subsubsection{Calculation of surface temperatures}

For the outermost surfaces:

$\theta \mathbf{s}_{1}=\left(\theta_{1} / R k_{1}-\theta_{a m b} / R h_{1}\right) /\left(1 / R k_{1}+1 / R h_{1}\right)$

and

$\theta_{S_{2 N}}=\left(\theta_{N} / R k_{N}-\theta_{\text {room }} / R h_{N}\right) /\left(1 / R k_{N}+1 / R h_{N}\right)$

For the remaining surfaces of the $i$ layers of the glazing system where surface $2 \mathrm{i}$ faces inward and surface 2i-1 faces outwards:

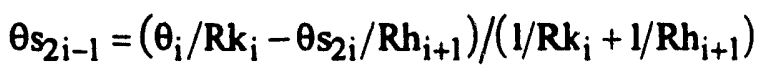

and

$\theta_{s_{i}}=\left(\theta_{i+1} / R k_{i+1}-\theta s_{2 i-1} / R h_{i+1}\right) /\left(1 / R k_{i+1}+1 / R h_{i+1}\right)$

Note that the front surface uses the value of the back surface temperature from the previous iteration. After new surface temperatures are calculated they are compared with the values from the previous iteration. If the absolute difference between the temperatures of both surfaces is greater than 0.01 than the program recalculates the surface temperatures based on the updated temperatures.

8.2.9 Calculation of a new temperature distribution using the heat flux residual, $\Delta_{\mathrm{j}}$ and the derivative with respect to temperature of the heat flux residual $\partial \Delta_{\mathrm{i}} / \partial \theta_{\mathrm{j}}$ :

$\theta_{k}=\theta_{k}^{0}+\delta \theta_{k}$

where $\theta_{k}^{0}$ is the value from the previous iteration and for small values of $\delta \theta_{k}$.

$\delta \theta_{k}=-\left[\partial \Delta_{k} / \partial \theta_{j}\right] \times \Delta_{j}^{0}$ 
An analytical expression for the temperature derivative of the residual is used in WINDOW. This expression is complicated due to nonlinear dependence of the heat transfer residual equation on the temperature. If $\delta \theta_{k}$ is greater than the maximum change in temperature from the previous iteration than $\delta \theta_{k}$ is replaced by $0.5 \delta \theta_{k}$. The new temperature is calculated using Eq. 8.2.9a. Finally to avoid oscillations in the numerical solution, WINDOW averages the current temperature profile with the previous temperature profile to obtain the final result for the current iteration.

\subsubsection{Check for convergence or maximum iterations}

If the maximum change in temperature is less than 0.01 than the solution is said to be converged. If after 30 iterations the convergence criterion is not met, WINDOW returns an error message.

\subsection{Condensation Calculation}

WINDOW calculates the relative humidity at which condensation will occur on the exposed surfaces using the method found in the ASHRAE Handbook of Fundamentals [1989]. The relative humidity at which condensation occurs is based on the glass surface temperature and the surrounding air temperature. First the saturation pressure is approximated for both temperatures using the following equation:

$$
\ln (P)=c 8 / \Theta+c 9+\operatorname{cl} 0 \times \Theta+c l 1 \times \Theta^{2}+\mathrm{cl} 2 \times \Theta^{3}+\mathrm{cl} 3 \times \ln (\Theta)
$$

Equation 8.3a is a function of the absolute temperatures: $\Theta=\theta+273^{\circ} \mathrm{K}$. The coefficients are:

\begin{tabular}{|l|l|l|l|l|l|}
\hline c8 & c9 & cl0 & c11 & cl2 & cl3 \\
\hline-5800.2206 & 1.3914993 & -0.04860239 & $0.41764768 \mathrm{e}-5$ & $-1.4452903 \mathrm{e}-7$ & 6.5459673 \\
\hline
\end{tabular}

The relative humidity, $\mathrm{RH}$, is then calculated:

$\mathrm{RH}=\mathrm{P}_{\mathrm{sat}} / \mathrm{P}_{\mathrm{amb}} \times 100$

Where $P_{\text {sat }}$ is the saturation pressure based on the absolute surface temperature of the glass and $P_{\text {amb }}$ is the saturation pressure based on the absolute temperature of the air. Equation $8.3 \mathrm{~b}$ is calculated twice, once using the ratio of the inner most glass surface conditions and the inside air conditions and again using the outer most glass surface conditions and the external environmental conditions. If the saturation pressure of the surface is greater than the saturation pressure of the surroundings, condensation will not occur.

\subsection{Effective Night Sky Temperature}

In this version of the program, the user is able to specify a sky temperature and a sky emittance in the ENVIRONMENTAL CONDIIONS LIBRARY. This feature is included to allow the user to anticipate the heat transfer from a window on a cold clear night. One of the undesirable circumstances of this condition is the formation of condensation on the outside of the glazing system. The sky temperature, $\theta_{\text {sky }}$ and the outside temperature, $\theta_{\text {out }}$, are defined by the user in the ENVIRONMENTAL CONDITIONS LIBRARY, see Fig. 8.1. The sky temperature is used to determine radiative exchange between the window and the environment. The ambient temperature, $\theta_{\mathrm{amb}}$, is used in Eq. 8.1 to determine the heat flux through the outermost layer and also to determine the outermost surface temperature, Eq. 8.2.8a. The ambient temperature is determined using the following equation: 
$\theta_{\text {amb }}=\left(h c_{\text {out }} \times \theta_{\text {out }}+h r_{\text {out }} \times \theta_{\text {sky }}\right) /\left(h c_{\text {out }}+h r_{\text {out }}\right)$

Note that if $\theta_{\text {sky }}$ is equal to $\theta_{\text {out }}$, the ambient temperature is equal to both the sky and the outdoor temperature. The effects of clear sky radiation on window performance is an area that would benefit from further investigation [Berdahl 1982].

\subsection{CONCLUSION}

WINDOW is a state-of-the-art computational tool for analyzing the thermal and optical properties of windows. The algorithms used in the program and documented in this paper are based on basic science and experimental analyses of specific components. Over the past several years, comparisons between WINDOW and experimental measurements on total window U-values have validated WINDOW's algorithms [Arasteh, 1986; Furler, 1988].

Several areas of the program are slated for technical as well as user-interface improvements. Technical improvements include a more accurate treatment of edge and frame film-coefficients, a procedure to analyze the angular solar/optical properties of coated glazings, and the ability to handle specialty products (skylights, greenhouse windows, etc.) more accurately. New features, such as the ability to create and analyze laminates are also being planned. User friendly improvements, such as seamless connections to RESFEN (which analyzes total window performance in typical homes throughout the United States) and FRAME (which analyzes 2-D heat transfer effects through window frames and edges) are in the planning process. 


\subsection{REFERENCES AND ACKNOWLEDGMENTS}

M. Acevido-Ruiz and D. Arasteh (1991). The Effect of Glazing System Dividers on Overall Window Heat Transfer, DRAFT, Building Technologies Group, Lawrence Berkeley Laboratory, Berkeley, CA 94720.

D. Arasteh (1989). An Analysis of Edge Heat Transfer in Residential Windows. Presented at the ASHRAE/DOE/BTECC/CIBSE Conference on Thermal Performance of the Exterior Envelopes of Buildings IV, Orlando, Florida, December 4-7, 1989.

D. Arasteh, S. Reilly, and M. Rubin (1989). A Versatile Procedure for Calculating Heat Transfer Through Windows, ASHRAE Transactions, Vol. 95, Part 2.

D. Arasteh, J. Hartmann, and M. Rubin (1986). Experimental Verification of a Model of Heat Transfer Through Windows. ASHRAE Transactions 1987; 93(1);1425-1431.

ASHRAE (1989). Handbook of Fundamentals, American Society of Heating, Refrigerating and Airconditioning Engineers, New York.

ASTM E891-87 (1987). Standard Tables for Terrestrial Direct Normal Solar Spectral Irradiance for Air Mass 1.5.

ASTM E308-90 (1990). Standard Test Method for Computing the Colors of Objects by Using the CIE System.

F. Beck (1993). "A Validation of the WINDOW 4/FRAME3 Linear Interpolation Methodology", DRAFT, Building Technologies Group, Lawrence Berkeley Laboratory, Berkeley, CA 94720.

P. Berdahl and R. Fromberg (1982). The Thermal Radiance of Clear Skies, Solar Energy, Vol. 29, No. 4, pp. 299-314.

S.M Elsherbiny, G.D. Raithby, and K.B.T. Hollands (1982). Heat Transfer by Natural Convection across Vertical and Inclined air layers. ASME Transactions February 1982, 104:96.

Enermodal Engineering (1991). FRAME -- A Computer Program to Evaluate the Thermal Performance of Window Frame Systems. Waterloo, Ontario, Canada: Enermodal Engineering Ltd.

R.A Furler, P. Williams, and F.K. Kneubühl (1988), Experimental and Theoretical Studies on the Energy Balance of Windows. NEFF Report Project Number 177.1.

R.A. Furler (1991). Angular Dependence of Optical Properties of Homogeneous Glasses, ASHRAE Transactions 97 (2), June 1991.

J.E. Kaufman (1984). IES Lighting Handbook, Reference Volume. Illuminating Engineering Society of North America.

R.J. Kee, J. Warnatz, J.A. Miller (1983). A FORTRAN computer code package for the evaluation of gasphase viscosities, conductivities, and diffusion coefficients. Sandia National Laboratories, March 1983; SAND83-8209. 
A. Konrad, and B.T. Larsen (1978). Encore - Canada; Computer Program for the Study of Energy Consumption of Residential Buildings in Canada. Proceedings, 3rd International Symposium on the Use of Computers for Environmental Engineering Related to Buildings, Banff, Alta.

J. Krochman (1978). Lichttechnik 1972 (I), 2 (1978) 66, Lichttechnik (II), 3 (1978) 104; cited by E. Ne'eman in the proceeding of the 1983 International Daylighting Conference February 1983; 71.

C.0. Petersen (1987). How is low-E Performance Criteria Determined? Glass Digest January 15, 1987; pp. 70-76.

M. Rubin, (1982) Calculating Heat Transfer Through Windows, Energy Research, Vol. 6, pp. 341-349.

M. Rubin, D. Arasteh, J. Hartmann (1987). A Correlation Between Normal and Hemispherical Emissivity of Low-Emissivity Coatings on Glass. International Communications in Heat and Mass Transfer, Vol. 14, No.5, Sept/Oct 1987, pp. 561-565.

S. Shakerin (1987). Wind-Related Heat Transfer Coefficient for Flat-Plate Solar Collectors. Journal of Solar Energy Engineering, May 1987; 109; pp. 108-110.

R. Siegel and J. Howell (1981). Thermal Radiation Heat Transfer, Hemisphere Publishing Corporation, New York, New York.

\section{ACKNOWLEDGMENTS}

This work was supported by the Assistant Secretary for Energy Efficiency and Renewable Energy, Office of Building Technologies, Building Systems and Materials Division of the U.S. Department of Energy under Contract No. DE-AC03-76SF00098. The authors wish to thank their colleagues at the Lawrence Berkeley Laboratory and at Enermodal Engineering for their contributions to this report. The authors appreciate the valuable discussions with scientists from the Florida Solar Energy Center and from the University of Massachusetts. The authors would also like to thank the industry users of the program who have served as reviewers of this and previous versions of the WINDOW program. 


\subsection{NOMENCLATURE}

This report discusses many different types of calculations. Many of these calculations have been reproduced from other sources. Every effort has been made to use nomenclature that is consistent with the original publications and is unambiguous within the context of this report. Some variables are used for different purposes throughout the report. Within the context of the section in which these variables appear there should be no confusion.

\begin{tabular}{|c|c|}
\hline$a^{*}, b^{*}, L^{*}$ & Color coordinates in CIE uniform color space \\
\hline A & Absorptance \\
\hline A & Area \\
\hline $\mathrm{cl}, \mathrm{c} 2$ & Constants used in Planck's function \\
\hline d & Glazing layer thickness \\
\hline $\mathrm{E}$ & Spectral weighting function \\
\hline g & Acceleration due to gravity \\
\hline Gr & Grashoff Number \\
\hline he & Convection Heat transfer (film) coefficient \\
\hline H & Horizontal Dimension \\
\hline k & Thermal Conductivity \\
\hline KEFF & Effective Conductivity \\
\hline $\mathrm{Mi}, \mathrm{j}$ & Infrared radiation transfer matrix \\
\hline $\mathbf{n}$ & Index of Refraction \\
\hline $\mathbf{N}$ & Inward Flowing Fraction \\
\hline $\mathbf{N}$ & Number of glazing layers in a glazing system \\
\hline $\mathrm{N}_{\mathrm{Hj}}, \mathrm{N}_{\mathrm{Vj}}$ & Number of horizontal and vertical dividers in the jth glazing system. \\
\hline $\mathrm{Nu}$ & Nusselt Number \\
\hline $\mathbf{P}$ & Pressure used to calculate relative humidity \\
\hline Q & Heat Flux \\
\hline $\mathbf{R}$ & Dummy variable representing tristimulous value ratios \\
\hline $\mathbf{R}$ & Ratios used in linear interpolations with FRAME 3.0 files \\
\hline $\mathbf{R}$ & Reflectance \\
\hline $\mathbf{R}$ & Resistance \\
\hline $\mathbf{R a}$ & Rayleigh Number \\
\hline Rh & Resistance due to conductance, includes radiative affects \\
\hline Rk & Resistance due to solid conductance \\
\hline RH & Relative Humidity \\
\hline RHG & Relative Heat Gain \\
\hline $\mathbf{S}$ & Column vector of radiative sources \\
\hline $\mathbf{S}$ & Spectral distribution of the illuminant \\
\hline SC & Shading Coefficient \\
\hline SHGC & Solar Heat Gain Coefficient \\
\hline t & Glazing system thickness \\
\hline tmod & Glazing system thickness determined by FRAME 3.0 \\
\hline $\mathrm{T}$ & Transmittance \\
\hline Tris & Visible transmittance \\
\hline tol & $\begin{array}{l}\text { Tolerance on a selected glazing system used with a frame/divider } \\
\text { modeled in the FRAME } 3.0 \text { program. }\end{array}$ \\
\hline $\mathrm{U}$ & U-value \\
\hline Umod & U-value determined by FRAME 3.0 \\
\hline V & Vertical dimension \\
\hline
\end{tabular}


w

$\mathrm{X}$

X, Y, Z

$x, y$

$\bar{x}_{10}, \bar{y}_{10}, \bar{z}_{10}$

\section{SYMBOLS}

$\alpha$

$\beta$

$\beta$

$\chi$

E

$\phi$

$\phi^{\prime}$

$\Phi$

$\Gamma$

K

$\lambda$

$\theta$

$\theta$ s

$\Theta$

$\rho$

$\bar{\rho}_{\text {bnz }}, \bar{\rho}_{\text {clr }}$

$\sigma$

$\bar{\tau}_{\text {bnz }}, \bar{\tau}_{\text {clr }}$

v

$\omega$

$\psi$

$\perp$

\section{SUBSCRIPTS}

abs

alt

amb

avg

C

D

DE

E

F

g
Width parallel to the plane of the window

Significant dimension used in divider correlations

Total tristimulus values

Chromaticity coordinates

Color Matching Functions based on CIE 1964 Supplementary

Standard $\left(10^{\circ}\right)$ Observer.

Absorptivity

Coefficient of thermal expansion

Multiple internal reflectance

Volumetric fraction of a component gas in a mixture

Emittance

Angle of incidence of beam radiation measured in air.

Angle of incidence of beam radiation measured in glass.

Angle determining windward or leeward side of a building

Auxiliary function used in spectral integrations

Extinction Coefficient

Wavelength

Layer midpoint temperature in degrees Celsius

Surface temperature in degrees Celsius

Absolute temperature in degrees Kelvin

Density

Reflectivity

Normalized reflectance of bronze and clear glass used to calculate the angular dependency of coated glazing layers.

Boltzmann's Constant

Transmisivity

Normalized transmittance of bronze and clear glass used to calculate the angular dependency of coated glazing layers.

Wind velocity

Gap width

Angle used to calculate the dominant wavelength

Perpendicular

Due to absorption

Alternate glazing system used in FRAME.

Ambient conditions

Average of the two surfaces of a glazing layer

Center-of-glass

Divider

Divider edge

Edge-of-glass

Frame

Significant gap spacing for divider correlations 
gap

glass

i

i

j

$\lambda$

$\max$

$\min$

opq

out

PVB

\section{$S$}

sat

sky

TOT

U

VIS

$\mathrm{x}$

ก

273

SUPERSCRIPTS

air, ar, $\mathrm{kr}, \mathrm{SF}_{6}$

b

f

sol

,

"
Area filled by gas in a multiple layer glazing system

Glass layer

A specific node

Frame Element

Glazing System

Spectral Property

Maximum U-value in Type IV model, See Fig. 6.5

Minimum U-value in Type IV model, See Fig. 6.5

Opaque components of the window

The external environmental conditions

Polyvinyl butyral layer

Gap between a suspended divider and the glazing layer surface

Saturation

Properties of the sky, may be different than the outside temperature Total Window Property

U-value

Total Window less the Frame Area

Classification of spectral average i.e. solar, visible, IR, UV

Hemispherical property

Evaluated at 270 Kelvin

Components in gas mixtures: air, argon, krypton, sulfur hexafluride Surface facing towards the interior of a building

Surface facing towards the outside

Solar property

Primary glazing system used in FRAME

Secondary glazing system used in FRAME 

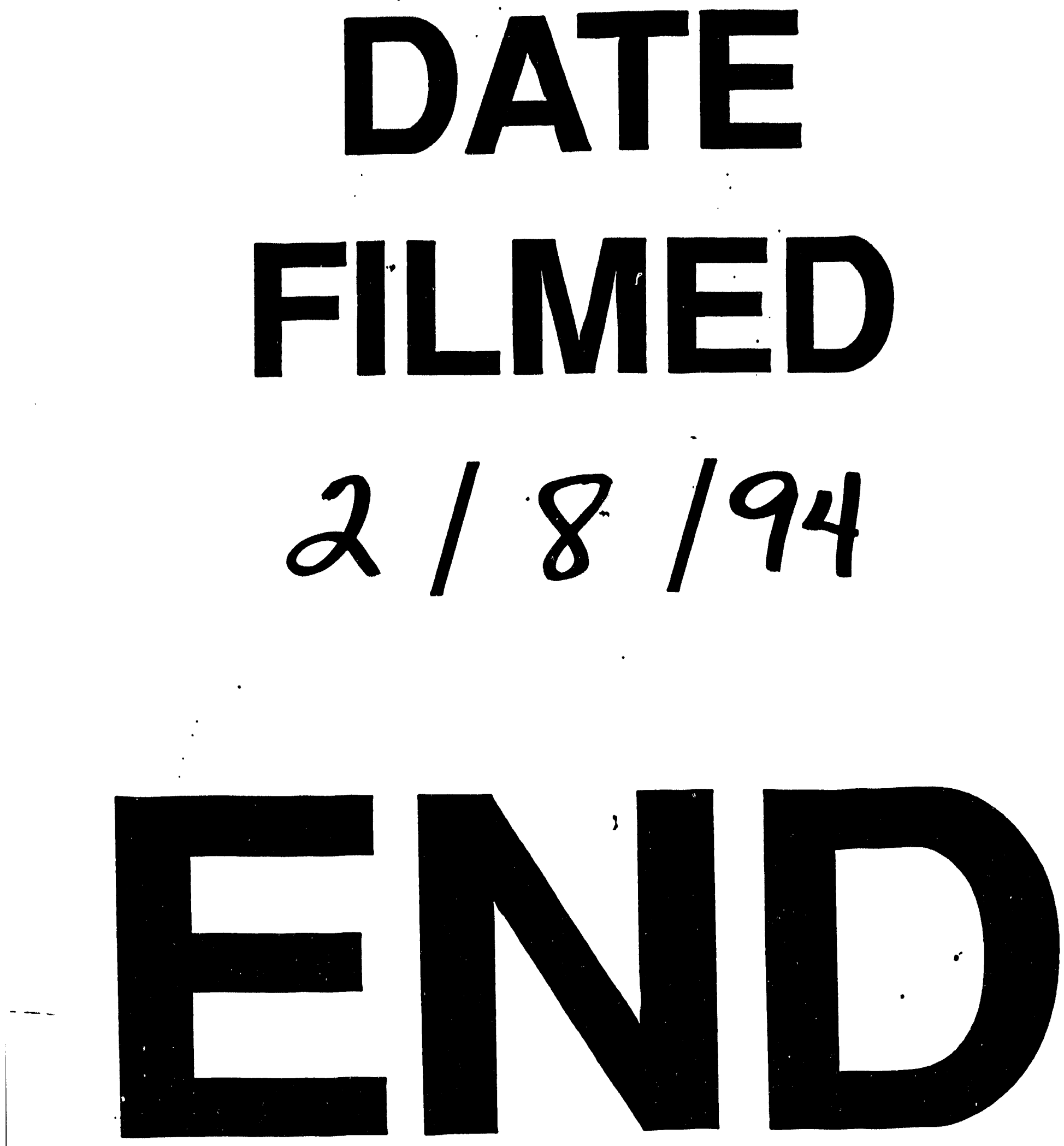


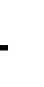

